\title{
Non-spherical abrasives with ordered mesoporous structures for chemical mechanical polishing
}

\author{
Peili Gao ${ }^{1,2 \dagger}$, Tingting Liu ${ }^{1 \dagger}$, Zhenyu Zhang ${ }^{1 *}$, Fanning Meng ${ }^{1}$, Run-Ping $\mathrm{Ye}^{2}$ and Jian Liu ${ }^{2,3^{*}}$
}

\begin{abstract}
The chemical mechanical polishing (CMP) technology has been widely used for surface modification of critical materials and components with high quality and efficiency. In a typical CMP process, the mechanical properties of abrasives play a vital role in obtaining the ultra-precision and damage-free surface of wafers for improvement of their performances. In this work, a series of fine structured rod-shaped silica $\left(\mathrm{RmSiO}_{2}\right)$-based abrasives with controllable sizes and diverse ordered mesoporous structures were synthesized via a soft template approach, and successfully applied in the sustainable polishing slurry for improving the surface quality of cadmium zinc telluride (CZT) wafers. Compared with commercial silica gel, solid and mesoporous silica spheres, the $\mathrm{RmSiO}_{2}$ abrasives present superior elastic deformation capacity and surface precision machinability on account of their mesoporous structures and rod shapes. Especially, ultra-precision surface roughness and relatively effective material removal speed were achieved by the CMP process using the $\mathrm{RmSiO}_{2}$ abrasives with a length/diameter $(L / d)$ ratio of 1 . In addition, a potential CMP mechanism of the developed polishing slurry to CZT wafer was elucidated by analyzing X-ray photoelectron spectra and other characterizations. The proposed interfacial chemical and mechanical effects will provide a new strategy for improving abrasives' machinability and precision manufacture of hard-to-machine materials.
\end{abstract}

Keywords: non-spherical abrasives, mesoporous structure, chemical mechanical polishing, interfacial mechanochemistry

\section{INTRODUCTION}

It is vital to achieve a globally planarizing surface of key materials and components with high quality and efficiency, which has a significant impact on the performances of devices in the major fields of aeronautics and astronautics, new energy devices, and so on [1-5]. Up to now, chemical mechanical polishing (CMP) technology is one of the most efficient approaches to obtain ultrasmooth and damage-free surfaces globally or locally by synergistically coupling the dual effects of mechanical grinding and chemical etching [6-9]. Moreover, the CMP conditions and slurry compositions directly determine the surface topography of polished wafers. However, the polishing effect of optimizing experimental parameters in the CMP process is limited [10-13]. Therefore, the development of a novel polishing slurry is desirable for improving the accuracy and efficiency of CMP [14-19]. As one of these components, abrasives are critical for removing the corrosion layer by mechanical grinding in a typical CMP process. Thus, the properties of abrasives play a vital role in the CMP performance [20-24].

So far, great efforts have been devoted to modifying the morphology [25-29], structure [30-37], and even surface chemical state of abrasives [38-41]. It is worth noting that the porous abrasives present potential applications in bringing the surface accuracy to an atomic level because of their low elasticity modulus (E) [42-45]. For example, as previously reported, porous silica abrasives turn out to be a better choice than conventional solid spheres due to their superior surface-flattening and damage-eliminating abilities, which can be attributed to their preferable elastic deformation ability $[43,46,47]$. In fact, the dependence of $E$ values on porous silica shell thicknesses in the core-

\footnotetext{
${ }^{1}$ Key Laboratory for Precision and Non-Traditional Machining Technology of Ministry of Education, Dalian University of Technology, Dalian 116024, China

${ }^{2}$ State Key Laboratory of Catalysis, Dalian Institute of Chemical Physics, Chinese Academy of Sciences, Dalian 116023, China

${ }^{3}$ DICP-Surrey Joint Centre for Future Materials, Department of Chemical and Process Engineering, and Advanced Technology Institute, University of Surrey, Surrey GU2 7XH, United Kingdom

† These authors contributed equally to this paper.

* Corresponding authors (emails: zzy@dlut.edu.cn (Zhang Z); jian.liu@surrey.ac.uk or jianliu@dicp.ac.cn (Liu J))
} 
mesoporous shell structured composites has been largely vindicated in some literatures [48-50]. Moreover, Jauffrès et al. [51] concluded employing nanoindentation and finite element model that mesoporous thin silica films with a lattice-ordered porosity exhibit a higher indentation modulus and a more elastic recovery behavior relative to random macroporous ones. In addition, the molecular dynamics (MD) simulation results also demonstrated that the friction force in nanoscale is linearly correlated to the quantity of chemically interacting atoms across the contact, which means the porous abrasives maybe possess well-defined tribo-chemical property due to their high specific surface area [52]. With further study, it is increasingly recognized that the porous abrasives have lower $E$ than non-porous ones due to their spring-like structure, which can promote their mechanical property and be beneficial to surface planarization.

However, most of the reports focused on the improvement of CMP quality by porous spherical abrasives, rather than the mechanism of porous structure affecting their elastic deformation properties and polishing effect. Therefore, the influence of the pore structure of porous abrasives on their mechanical properties is inexplicit, which would undoubtedly restrain the research on the improvement of abrasive properties. Furthermore, it is well-known that CMP quality and efficiency are restricted mutually, and thus the improvement of polishing efficiency by porous abrasives is restricted even though it is beneficial for enhancing the precision of CMP process.
However, there is no report to modify abrasives in multiple properties (e.g., the porous structure and morphology) to improve their polishing quality and efficiency simultaneously.

Herein, a series of rod-shaped mesoporous silica particles $\left(\mathrm{RmSiO}_{2}\right)$ with diverse length to diameter $(L / d)$ ratios were designed to investigate the effects of both mesoporous structure and rod shape on the tribo-chemical ability of abrasives. Moreover, a kind of sustainable polishing slurry was developed based on these particles. Cadmium zinc telluride (CZT) is a crucial third-generation semiconductor material for high-energy detectors at room temperature. However, owing to its soft and brittle texture, CZT wafers are regarded as a hard-to-machine material [53-56]. Therefore, the prepared slurry was applied in the CMP process of CZT wafers to make a thorough inquiry into the CMP performance of this series of $\mathrm{RmSiO}_{2}$ abrasives. The schematic illustration of the overall experimental design for the synthesis of $\mathrm{RmSiO}_{2}$ abrasives and the CMP process is shown in Fig. 1. Furthermore, the dependency of porous structure and mechanical properties of $\mathrm{RmSiO}_{2}$ particles on different $\mathrm{L} / d$ ratios was investigated by measuring the $E$ values via the atom force microscopy (AFM) non-indentation technique. In addition, the possible CMP mechanism of the developed polishing slurry containing $\mathrm{RmSiO}_{2}$ abrasives to CZT wafers was proposed, which might provide further insights to disclose the CMP mechanism of other materials.

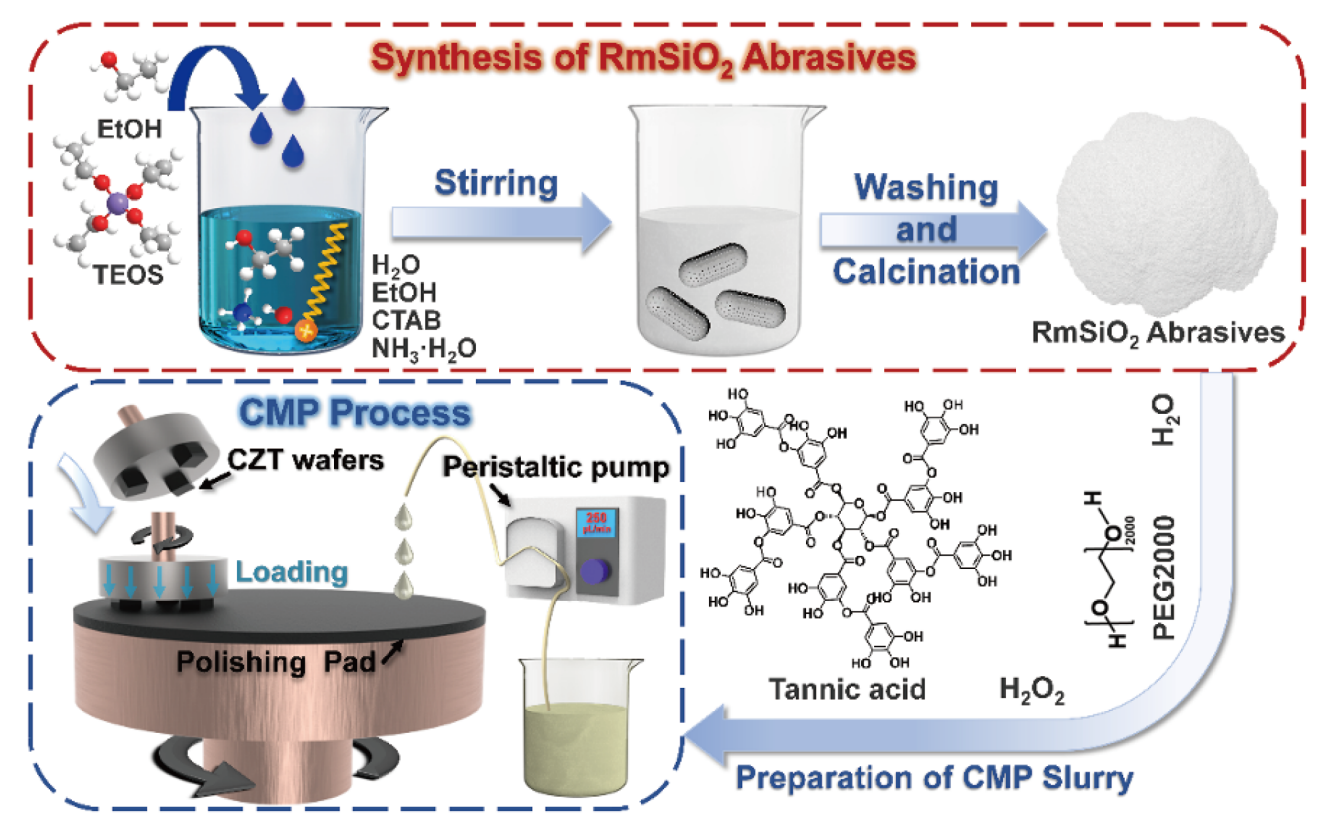

Figure 1 Schematic illustration of the overall experimental design for the synthesis of $\mathrm{RmSiO}_{2}$ abrasives and the CMP process. 


\section{EXPERIMENTAL SECTION}

\section{Chemicals}

Absolute ethanol (EtOH, 99.7\%), ammonia solution $\left(\mathrm{NH}_{3} \cdot \mathrm{H}_{2} \mathrm{O}, 25.0 \%-28.0 \%\right)$, hexadecyltrimethylammonium bromide (CTAB, 99.0\%), tetraethyl orthosilicate (TEOS, $28.4 \%$ ), and tannic acid (TA) were purchased from Sinopharm Chemical Reagent Co., Ltd. Hydrogen peroxide $\left(\mathrm{H}_{2} \mathrm{O}_{2}, 30 \%\right)$ was purchased from Tianjin Kemiou Chemical Reagent Co., Ltd. The commercial silica sol $\left(\mathrm{SiO}_{2}\right.$, $60 \mathrm{wt} \%)$ with an average diameter of $60 \mathrm{~nm}$ for contrast experiment was purchased from Dalian Snowchemical Co., Ltd., whose transmission electron microscopy (TEM) image is shown in Fig. S1a. All reagents in the experiments were of analytical grade and used directly without any further purification. Deionized water $\left(\mathrm{DI} \mathrm{H}_{2} \mathrm{O}\right)$ was used throughout all experiments.

\section{Synthesis of $\mathrm{RmSiO}_{2}$ abrasives}

$\mathrm{RmSiO}_{2}$ particles were prepared via a modified Stöber method. The molar ratios of reactants for synthesizing $\mathrm{RmSiO}_{2}$ particles with different $L / d$ ratios are listed in Table S1. The synthesis process is as follows: primarily, certain amounts of $\mathrm{DI} \mathrm{H}_{2} \mathrm{O}, \mathrm{EtOH}$ and $\mathrm{NH}_{3} \cdot \mathrm{H}_{2} \mathrm{O}$ solution were mixed at room temperature under a stirring speed at $200 \mathrm{rmin}^{-1}$. Then CTAB as a structure-directing agent was dissolved into the mixture and treated in an ultrasonic bath for $15 \mathrm{~min}$ to form a self-assembly template solution. Subsequently, TEOS as a silica source agent mixed with EtOH was added dropwise into the template solution above under continuous stirring within 23-55 min. A homogeneous milky colloidal solution was gradually formed after reaction for $4 \mathrm{~h}$. Ultimately, the asprepared $\mathrm{RmSiO}_{2}$ particles were collected by centrifugation, washed with $\mathrm{DI} \mathrm{H}_{2} \mathrm{O}$ and $\mathrm{EtOH}$ several times and dried overnight at $60^{\circ} \mathrm{C}$. Finally, $\mathrm{RmSiO}_{2}$ particles with different $L / d$ ratios were synthesized successfully after soft template removal by calcining at $550^{\circ} \mathrm{C}$ for $4 \mathrm{~h}$ in air. For comparing the mechanical properties of the as-synthesized mesoporous $\mathrm{RmSiO}_{2}$, solid and mesoporous silica spheres $\left(\mathrm{sSiO}_{2}\right.$ and $\left.\mathrm{mSiO}_{2}\right)$ abrasives, $\mathrm{sSiO}_{2}$ and $\mathrm{mSiO}_{2}$ spheres with a uniform particle size of 422 and $391 \mathrm{~nm}$ were prepared through a typical Stöber synthesis (see Supplementary information for experimental details), respectively. The TEM images are shown in Figs S1b and S2a.

\section{CMP tests}

CZT wafers with $1.0 \mathrm{~cm} \times 1.0 \mathrm{~cm}$ in dimension and $1.3-1.4 \mathrm{~mm}$ in thickness, grown by the modified Bridg- man method were used as polishing substrates. In the experiments, three pieces of CZT wafers were glued by using molten paraffin wax along the periphery of an aluminum disk with $100 \mathrm{~mm}$ diameter evenly. The lapping and CMP experiments were performed on a precise polishing equipment (UNIPOL-1200S, Shenyang Kejing auto-instrument Co., Ltd., China) with a corrosion-resistant plate. Before the CMP experiment, the CZT wafers should be ground with 4000-grit $\mathrm{SiC}$ paper first to obtain a relatively flat surface. During grinding, the load pressure was $30 \mathrm{kPa}$, and the rotation speed of $\mathrm{SiC}$ paper was $50 \mathrm{r} \mathrm{min}^{-1}$. DI $\mathrm{H}_{2} \mathrm{O}$ was used as a grinding fluid and supplied at a flow rate of $10 \mathrm{~mL} \mathrm{~min}^{-1}$. After $1 \mathrm{~min}$ grinding, the CZT pieces were rinsed with $\mathrm{DI} \mathrm{H}_{2} \mathrm{O}$ and blow-dried with compressed air for further precise polishing.

The commercial $\mathrm{SiO}_{2}, \mathrm{mSiO}_{2}, \mathrm{sSiO}_{2}$, and $\mathrm{RmSiO}_{2}$ abrasives with different $L / d$ ratios were used to prepare CMP slurries with a concentration of $45.5 \mathrm{~g} \mathrm{~L}^{-1}$ in aqueous suspensions. In addition, $\mathrm{H}_{2} \mathrm{O}_{2}$ solution, polyethylene glycol $\left(M_{\mathrm{w}}=2000\right.$, PEG2000), and TA were applied as oxidant, dispersant and $\mathrm{pH}$ adjuster, respectively. The volume ratio between aqueous suspensions and $\mathrm{H}_{2} \mathrm{O}_{2}$ solution was 6.5, and $5 \mathrm{wt} \%$ PEG2000 was added in slurries based on the weight of abrasives. The $\mathrm{pH}$ value of CMP slurries ranging from 3.95 to 4.05 was adjusted by adding $1 \mathrm{~mol} \mathrm{~L}^{-1} \mathrm{TA}$ dropwise. Subsequently, the CMP slurries were treated ultrasonically for $30 \mathrm{~min}$ before CMP experiments. During the CMP experiment, the $\mathrm{SiC}$ paper should be replaced by a black porous neoprene pad (MD-chem, NX-MT), and the parameters of the CMP process were set as per Table S2. After CMP, the CZT pieces were taken down by molten paraffin wax and cleaned with $\mathrm{EtOH}$ at $80^{\circ} \mathrm{C}$ in an ultrasonic bath, followed by wiping clean with a dust-free cloth.

\section{Characterization}

The morphologies of the $\mathrm{RmSiO}_{2}$ particles were characterized by TEM (HITACHI HT7700) at an acceleration voltage of $100 \mathrm{kV}$ and scanning electron microscopy (SEM, FEI Quanta 200F) operating at $20 \mathrm{kV}$. High-resolution SEM (HRSEM, HITACHI S5500) were carried out to track the mesopore distribution on the $\mathrm{RmSiO}_{2}$ particle surface. The samples for TEM, SEM and HRSEM were prepared by dispersing them into EtOH under ultrasonic treatment and dropping the mixture onto a commercial carbon film-coated copper grid and conductive glue, respectively. The size distribution of the $\mathrm{RmSiO}_{2}$ particles was obtained by counting 80 nanoparticles from SEM images at random and recording their 
length and diameter values. Nitrogen $\left(\mathrm{N}_{2}\right)$ adsorption/ desorption isotherms were performed with a Micromeritics ASAP 2469 apparatus to detect the surface areas and pore volumes of the $\mathrm{RmSiO}_{2}$ particles, based on the Brunauer-Emmett-Teller (BET) and Barrett-Joyner-Halenda $(\mathrm{BJH})$ methods, respectively. The powder X-ray diffraction (XRD) patterns and corresponding low-angle XRD patterns were undertaken on a Rigaku D/ Max2500PC diffractometer with $\mathrm{Cu} \mathrm{Ka}$ radiation $(\lambda=$ $1.5418 \AA$ ) over the $2 \theta$ range of $5^{\circ}-80^{\circ}$ and $0.5^{\circ}-8^{\circ}$, respectively. Besides, the scanning speed at room temperature was $5^{\circ} \mathrm{min}^{-1}$ and $1^{\circ} \mathrm{min}^{-1}$, respectively. The $E$ measurements were conducted by AFM (Bruker) with the contact mode, and the antimony-doped Si probe with a spring contact of $72.488 \mathrm{~N} \mathrm{~m}^{-1}$ was used to compress the particle to deform for $12 \mathrm{~nm}$.

The topography of CZT wafer surface before and after CMP experiments with different abrasives was imaged by an optical microscope (MX-40, Olympus, Japan) and AFM (Multimode Nanoscope V) using a commercial silicon probe. The cantilever had a pyramid-shaped tip with a curvature of the apex around $20 \mathrm{~nm}$. The scan areas with a resolution of $250 \mathrm{px} \times 250 \mathrm{px}$ were set as $5 \mu \mathrm{m} \times 5 \mu \mathrm{m}$ and scan speeds were $1 \mathrm{~Hz}$. For objectively evaluating the polishing accuracy, the average mean roughness $\left(R a_{\text {average }}\right)$ and root-mean-square (RMS) roughness $\left(R q_{\text {average }}\right)$ values of surfaces of polished CZT wafers were acquired by measuring randomly five selected locations and calculating their average values. The two-dimensional (2D) and 3D images shown are the height maps of CZT wafers with the lowest $R a$ values among the five selected locations. The material removal rate (MRR, $\mathrm{nm} \mathrm{h}^{-1}$ ) could be calculated as Equation (1):

$\operatorname{MRR}=\frac{\Delta m \times 10^{6}}{\rho S \tau}$,

where $\Delta m$ is the mass loss of CZT wafers after polishing $(\mathrm{g}) ; \rho$ is the density of CZT wafers $\left(\rho_{\mathrm{CZT}}=5.925 \mathrm{~g} \mathrm{~cm}^{-3}\right)$; $S$ is the total contact area between the polishing pad and CZT substrates $\left(\mathrm{mm}^{2}\right) ; \tau$ is the polishing time (h).

The Tafel polarization curves were recorded by an advanced electrochemical system (CHI 760E, Chinstruments Co., Ltd.) with a three-electrode system. The referenced and auxiliary electrodes were saturated calomel electrode (SCE) of potassium chloride $(\mathrm{KCl})$ and platinum (Pt) with a purity of $99.99 \%$, respectively. X-ray photoelectron spectroscopy (XPS) measurements were performed on an Axis Ultra ${ }^{\text {DLD }}$ KRATOS spectrometer using a monochromated $\mathrm{Al} \mathrm{Ka}$ X-ray source $(h v=1486.6 \mathrm{eV})$. All binding energies were referenced to the $\mathrm{C} 1 \mathrm{~s}$ peak $(284.6 \mathrm{eV})$. Fourier-transform infrared
(FTIR) spectroscopy measurements were performed on a Nicolet 6700 spectrometer to detect the vibrational peaks of $\mathrm{TA}$ and catechol- $\mathrm{Cd}^{2+} / \mathrm{Zn}^{2+}$ mono-complexes. In order to obtain the complexes, the CZT substrates were ground into a powder, and immersed in a solution composed of DI $\mathrm{H}_{2} \mathrm{O}, \mathrm{H}_{2} \mathrm{O}_{2}$ and TA with $\mathrm{pH}$ of 4 for $4 \mathrm{~h}$. Finally, the solution was dried in a vacuum oven at $60^{\circ} \mathrm{C}$ to obtain a kind of brown powder as the chelating product.

\section{RESULTS AND DISCUSSION}

\section{Structural characterizations of $\mathrm{RmSiO}_{2}$}

$\mathrm{RmSiO}_{2}$ particles with different $L / d$ ratios of $1,1.5,2,2.5$ and $3\left(\mathrm{RmSiO}_{2}-1, \mathrm{RmSiO}_{2}-1.5, \mathrm{RmSiO}_{2}-2, \mathrm{RmSiO}_{2}-2.5\right.$ and $\mathrm{RmSiO}_{2}-3$, respectively) were prepared via a modified Stöber method. Their morphologies and structural characterizations via SEM and TEM are shown in Fig. 2. The uniform rod-shaped structures can be seen clearly from SEM images in the first column of Fig. 2 with a regular and homogeneous shape, and the $\mathrm{RmSiO}_{2}$ particles are highly monodispersed with no aggregation between them. TEM images (Fig. 2) also indicate all the $\mathrm{RmSiO}_{2}$ particles with different $L / d$ ratios have similar rod-shaped structures like cylinders with removed edges. The average sizes of the $\mathrm{RmSiO}_{2}$ particles were calculated through their narrow length and diameter distributions, which reveal the change in $L / d$ ratios was mainly due to the increase in their length.

Due to the electron contrast possibly resulting from the existence of porous frameworks [57], it is observed that mesopores and channels distribute radially on the particles in TEM images. In order to detect the distribution of mesopores more clearly, the individual particles with $L / d$ ratios of 1,2, 3 were magnified. As confirmed by HRSEM images (Fig. 3), abundant mesopores scatter throughout the particles, causing their smooth outer surface to be relatively porous. However, it is worth noting that the distributions of pores are slightly diverse with the change of $L / d$ ratios. The $\mathrm{RmSiO}_{2}-1$ particle possesses relatively dense pores, and most of them are arranged in parallel lines to form well-ordered hexagonal pore structures, as shown in Fig. $3 \mathrm{~d}$. However, the bigger the $L / d$ ratios, the looser the pores. The degrees of pore structural order gradually decrease with increases in $L / d$ ratios, until the well-ordered porous frameworks vanish on the surface of the $\mathrm{RmSiO}_{2}-3$ particle. This may be attributed to the quantitative template agent used. According to the Stöber method, limited CTAB plays a role as a structural director in the formation of $\mathrm{RmSiO}_{2}$ particles. When the length of $\mathrm{RmSiO}_{2}$ particles becomes longer, the pores constructed 


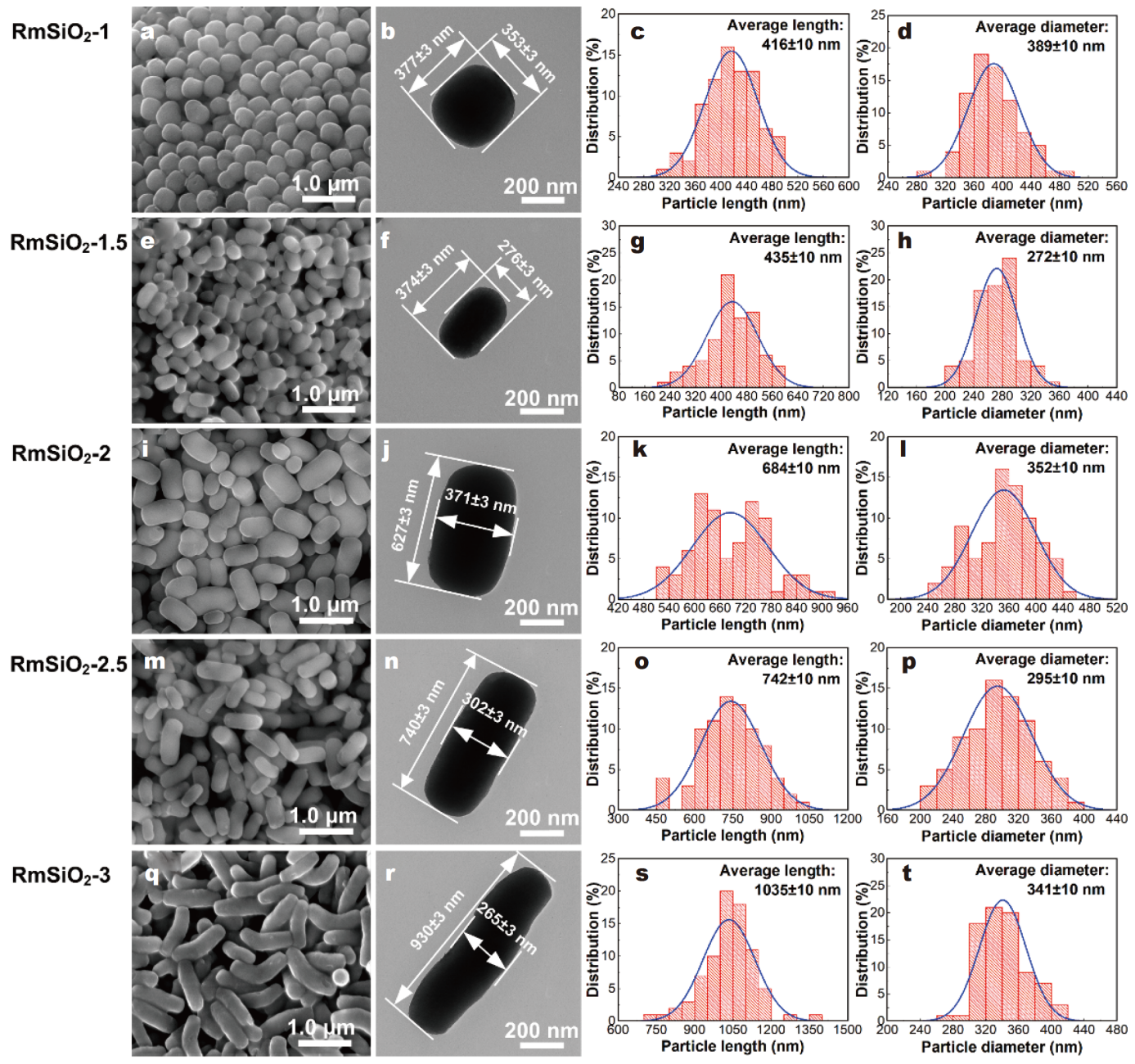

Figure 2 SEM images (a, e, i, m, q), TEM images (b, f, j, n, r), particles length (c, g, k, o, s), and diameter (d, h, l, p, t) distributions of RmSiO particles with different $L / d$ ratios.
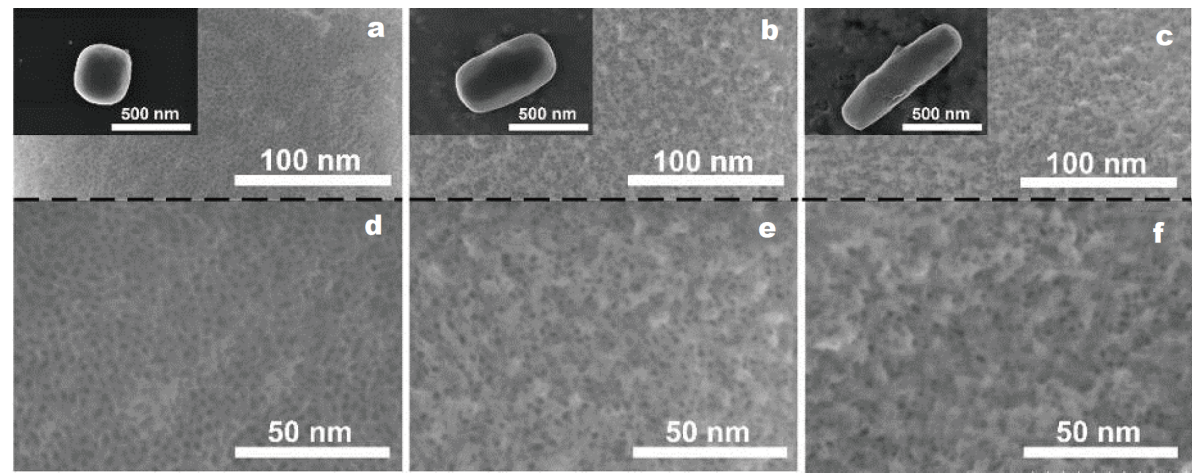

Figure 3 HRSEM images with different magnifications of $\mathrm{RmSiO}_{2}-1$ (a, d), $\mathrm{RmSiO}_{2}-2$ (b, e), and $\mathrm{RmSiO}_{2}-3$ (c, f).

by a fixed amount of CTAB become less compact, so that the pores density and degree of their structural order decrease as the $L / d$ ratios of $\mathrm{RmSiO}_{2}$ particles increase.
To further explore the porous nature of the $\mathrm{RmSiO}_{2}$ particles, the powder XRD patterns were carried out. All the wide-angle XRD patterns (Fig. $4 \mathrm{~b}$ ) of the $\mathrm{RmSiO}_{2}$ 


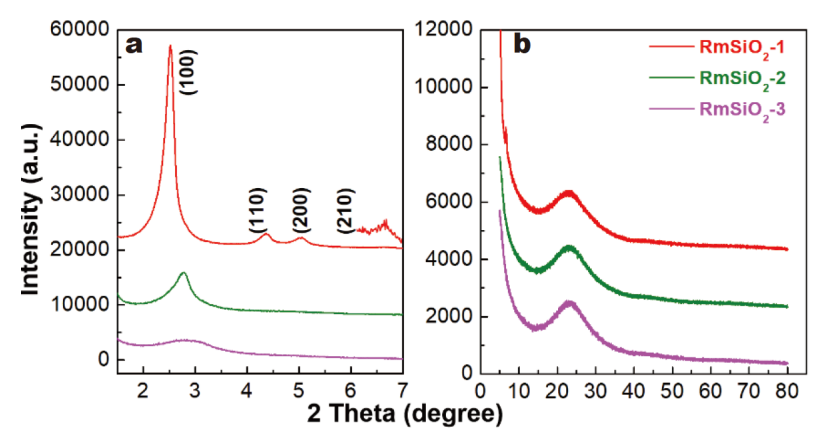

Figure 4 (a) Powder low-angle XRD patterns and (b) wide-angle XRD patterns of $\mathrm{RmSiO}_{2}$ particles with different $L / d$ ratios.

particles with different $L / d$ ratios present only one broad diffraction peak located near $23^{\circ}$, revealing the formation of amorphous silicon in the as-synthesized samples [58]. However, their low-angle XRD patterns (Fig. 4a) exhibit entirely different characteristics. Obviously, three discernible diffraction peaks and one weak peak, corresponding to (100), (110), (200) and (210) planes, respectively, appear only in low-angle XRD patterns of $\mathrm{RmSiO}_{2}-1$, which demonstrates the $\mathrm{RmSiO}_{2}-1$ has classical well-ordered hexagonal pore structures $[59,60]$. However, with increasing $L / d$ ratios, not only do the intensities of the first peaks matched with (100) plane in low-angle XRD patterns of $\mathrm{RmSiO}_{2}-2$ and $\mathrm{RmSiO}_{2}-3$ become weaker, but the positions of the peaks also shift to higher angles. The reason is that the order degrees of pore structure decrease and the pore distribution is more concentrated, respectively. On account of the weakening of intensities and position shift of peaks, the low-resolution peaks cannot be displayed in low-angle XRD patterns.

Furthermore, the values of $d_{(100)}$ and $a_{(100)}$, representing interplanar spacing and pore center distance, can be calculated using $2 \theta$ values of (100) planes in low-angle XRD patterns via Bragg's Law. The computed $a_{(100)}$ values of $\mathrm{RmSiO}_{2}-1, \mathrm{RmSiO}_{2}-2$ and $\mathrm{RmSiO}_{2}-3$ are 4.04, 3.69, and 3.51 , respectively, implying the pores are increasing centralized with the increase of $L / d$ ratios, which can be confirmed by HRSEM observations (in Fig. 3e, f). This is completely contrary to the changing trend of pore density on the whole, as shown in Fig. 3, that the pores of $\mathrm{RmSiO}_{2}$ particles become sparse gradually with their size enlarging. This unique mesostructure arrangement on the $\mathrm{RmSiO}_{2}$ surface can be attributed to their porous frameworks constructed by CTAB micelles. As the micelle arrangement is susceptible to the reaction environment during the self-assembly process, the pore structures with different local and global permutations are formed when the ratios of reactants are different. Therefore, pores of $\mathrm{RmSiO}_{2}-1$ particle are relatively unconsolidated than $\mathrm{RmSiO}_{2}-2$ and $\mathrm{RmSiO}_{2}-3$ within the small concentratedly distributed range, even though it has compact pores with well-ordered hexagonal structures overall.

$\mathrm{N}_{2}$ adsorption/desorption isotherms (Fig. S3) provide further insight into porosity information (e.g., pore size, surface area and pore volume) of the $\mathrm{RmSiO}_{2}$ particles. According to IUPAC, the isotherms can be assigned to the type IV isotherms with $\mathrm{H} 1$ hysteresis loops, implying the presence of typical mesoporous structure [61]. Moreover, the corresponding pore size distribution curves (Fig. S3b) were estimated by the $\mathrm{BJH}$ model using data from adsorption branches. The average pore diameters of $\mathrm{RmSiO}_{2}$ particles with different $L / d$ ratios are between 2 and $2.5 \mathrm{~nm}$, which is in agreement with the mesoporous frameworks indicated by HRSEM and powder XRD results. On the other hand, the peak of $\mathrm{RmSiO}_{2}$ 1 centered at $2.4 \mathrm{~nm}$ is relatively posterior and sharper than others, which means that the $\mathrm{RmSiO}_{2}-1$ has more large-sized pores than $\mathrm{RmSiO}_{2}-2$ and $\mathrm{RmSiO}_{2}-3$. This could be attributed to channel collapse and pore expansion in $\mathrm{RmSiO}_{2}$-1's dense pore structure during the calcination process of silicate condensation. It is difficult for pores of $\mathrm{RmSiO}_{2}-2$ and $\mathrm{RmSiO}_{2}-3$ to expand due to their sparse pore arrangements overall, but their pores with a short pore center distance can expand easily within the small compact range. Therefore, the number of largesized pores on $\mathrm{RmSiO}_{2}-2$ and $\mathrm{RmSiO}_{2}$-3's surfaces is less and their average pore diameters are relatively smaller than that of $\mathrm{RmSiO}_{2}-1$ particles. Besides, the calculated BET surface area and $\mathrm{BJH}$ cumulative pore volume of $\mathrm{RmSiO}_{2}-1$ are $1105 \mathrm{~m}^{2} \mathrm{~g}^{-1}$ and $0.78 \mathrm{~cm}^{3} \mathrm{~g}^{-1}$, respectively, while those of $\mathrm{RmSiO}_{2}-2$ and $\mathrm{RmSiO}_{2}-3$ slightly decrease. This confirms that a large number of large-sized pores exist in $\mathrm{RmSiO}_{2}-1$ compared with $\mathrm{RmSiO}_{2}-2$ and $\mathrm{RmSiO}_{2}-3$.

As seen from the above figures (Figs 3, 4 and Fig. S3), the prepared $\mathrm{RmSiO}_{2}$ particles with different $L / d$ ratios have diverse mesoporous structures. Since the porous characteristics of abrasives have a great influence on their mechanical properties, the $E$ values of $\mathrm{RmSiO}_{2}$ and $\mathrm{sSiO}_{2}$ particles were calculated via the Johnson-Kendall-Roberts (JKR) model in AFM nano-compression measurement, shown in Fig. S4. It can be found that the $E$ value of the $\mathrm{sSiO}_{2}$ sphere is $6.078 \mathrm{GPa}$ and higher than that of $\mathrm{RmSiO}_{2}$ particle (2-4 GPa), confirming the porous abrasives deform more elastically than non-porous ones in a squeezed state. Moreover, the $E$ value of $\mathrm{RmSiO}_{2}$ particles increases with the increase of $L / d$ ratios. The $\mathrm{RmSiO}_{2}-1$ particle 
with abundant compact pores possesses the lowest $E$, implying its favorable deformation capacity and mechanical performance in the CMP process. By contrast, the $\mathrm{RmSiO}_{2}-3$ particle is relatively less elastic, and more importantly, its $E$ value is close to that of the $\mathrm{RmSiO}_{2}-2$. This might be because $\mathrm{RmSiO}_{2}-2$ and $\mathrm{RmSiO}_{2}-3$ have similar unconsolidated porous frameworks with out-oforder pore arrangements. Due to the pores of $\mathrm{RmSiO}_{2}-2$ particles are arranged more closely and orderly than for the $\mathrm{RmSiO}_{2}-3$ ones, $E$ values of $\mathrm{RmSiO}_{2}$-2 particles are slightly lower. The measured results of Young's modulus reveal that the pores' arrangements and order degrees of abrasives have an impact on their mechanical properties.

CMP performance and mechanical mechanism of $\mathrm{RmSiO}_{2}$ It is commonly recognized that surface quality and material removal speed are two crucial evaluating indicators of CMP performance, which are determined by the characterizations of abrasives and CMP conditions. Under the identical experimental processes, the chemical and mechanical nature of $\mathrm{RmSiO}_{2}$ particles has a decisive impact on polishing performance.

The surface quality of polished CZT wafers can be evaluated through their surface topographies, which were achieved by optical microscope and AFM. The optical images of CZT wafers after grinding and polishing are observed with a large area of $1.5 \mathrm{~mm} \times 2.0 \mathrm{~mm}$ in Fig. S5. As can be seen in Fig. S5b, an abundance of mechanical scratches and cracks are distributed deeply on CZT wafers after grinding for $1 \mathrm{~min}$. Conversely, the polished surfaces using the commercial and as-synthesized abrasives are perfectly flat and smooth like mirrors, revealing apparent removal of micro-sized asperities and grooves. However, compared with the spotless surface of CZT wafers polished with $\mathrm{sSiO}_{2}, \mathrm{mSiO}_{2}$, and $\mathrm{RmSiO}_{2}$ abrasives, a few residual stains and micro-scratches have remained on the surface polished with commercial abrasives. This may be caused by their wide distribution of particle sizes, so the tiny ones are so sticky that cannot be removed and then embedded in the surface to cause micro-scratches. Moreover, the small pits on the surface of CZT wafer polished with $\mathrm{sSiO}_{2}$ abrasives have a more distinct appearance than that of CZT wafers polished with $\mathrm{mSiO}_{2}$ and $\mathrm{RmSiO}_{2}$ abrasives. This indicates $\mathrm{sSiO}_{2}$ abrasives would leave deeper grinding trails than $\mathrm{mSiO}_{2}$ and $\mathrm{RmSiO}_{2}$ abrasives when they bear the same loads in the CMP process.

To further explore the surface features of CZT wafers after polishing with $\mathrm{RmSiO}_{2}, \mathrm{mSiO}_{2}$, and $\mathrm{sSiO}_{2}$ particles, AFM images scanning over $5 \mu \mathrm{m} \times 5 \mu \mathrm{m}$ regions and cross-sectional profiles (Fig. 5) were tracked. For pixels in AFM 2D and 3D images, the lighter the pixels, the higher their height, so an area filled with approximate colors represents that the corresponding surface has superior surface flatness and accuracy. Comparing five AFM 2D images (Fig. 5a-e) of CZT wafers polished with $\mathrm{SiO}_{2}$, $\mathrm{mSiO}_{2}$, and $\mathrm{RmSiO}_{2}$ abrasives, the most uniform color can be found in the image of polished CZT wafer using $\mathrm{RmSiO}_{2}-1$, while the worst is the wafer using $\mathrm{sSiO}_{2}$. Moreover, the sequence of $R a$ values calculated using their height data are $0.259,0.333,0.339,0.376$, and $0.412 \mathrm{~nm}$, matching to the surface accuracies of CZT wafers polished with $\mathrm{RmSiO}_{2}-1, \mathrm{RmSiO}_{2}-3, \mathrm{RmSiO}_{2}-2$, $\mathrm{mSiO}_{2}$, and $\mathrm{sSiO}_{2}\left(\mathrm{CZT}_{\mathrm{R} 1}, \mathrm{CZT}_{\mathrm{R} 3}, \mathrm{CZT}_{\mathrm{R} 2}, \mathrm{CZT}_{\mathrm{m}}\right.$, and $\mathrm{CZT}_{s}$ wafers), respectively. In addition, it is worth mentioning that the variation trend of $R a_{\text {average }}$ values and $R q_{\text {average }}$ values in Fig. $5 f$ reflects the same sequence with that. It can be visually seen from the $R a$ values that the CZT wafer polished with $\mathrm{RmSiO}_{2}$ abrasives realizes more precision surface compared with that using $\mathrm{mSiO}_{2}$ and $\mathrm{sSiO}_{2}$ spheres, implying that the as-synthesized $\mathrm{RmSiO}_{2}$ abrasives have greater surface machinability than $\mathrm{mSiO}_{2}$ and $\mathrm{sSiO}_{2}$ spheres. Moreover, the surface smoothness achieved by $\mathrm{RmSiO}_{2}-1$ is the highest, revealing its superiority in ultra-precision manufacturing.

Since the roughness values cannot describe the spatial variation at the same horizontal line, they may be misled by mutational peak or valley values, while the profile of the cross-sectional lines may indicate it well. Therefore, the section lines were derived from AFM 2D height images of $\mathrm{CZT}_{\mathrm{R} 1}, \mathrm{CZT}_{\mathrm{R} 2}, \mathrm{CZT}_{\mathrm{R} 3}, \mathrm{CZT}_{\mathrm{m}}$, and $\mathrm{CZT}_{\mathrm{s}}$ wafers along central dotted lines, as presented in Fig. 5g. The measured peak to valley $(\mathrm{PV})$ values of their profiles were determined to be $1.36,2.24,1.74,2.82$, and $2.85 \mathrm{~nm}$, respectively. Both the gentlest fluctuation and smallest $\mathrm{PV}$ value of profile taken from the image of $\mathrm{CZT}_{\mathrm{R} 1}$ wafer indicate the reduced topography variations and improved surface quality achieved by $\mathrm{RmSiO}_{2}-1$ abrasives. Furthermore, the AFM 3D images (Fig. 5h-l) give a more intuitive view of their topographies. As noticed, the surface undulation is characterized obviously in images of $\mathrm{CZT}_{\mathrm{R} 2}, \mathrm{CZT}_{\mathrm{m}}$, and $\mathrm{CZT}_{\mathrm{s}}$ wafers (Fig. 5i, k, l), and an evident pit can be observed on the $\mathrm{CZT}_{\mathrm{R} 3}$ wafer surface (Fig. $5 \mathrm{j}$ ). This is the reason why they have higher $R a$ values, and perhaps the poorer surface quality is resulting from some indentations of embedded $\mathrm{sSiO}_{2}, \mathrm{mSiO}_{2}$, and $\mathrm{RmSiO}_{2}$ particles with large size or stiffness.

According to the theoretical, experimental and simulated literature reports, it is widely believed that porous abrasives present more softness and elasticity than solid 

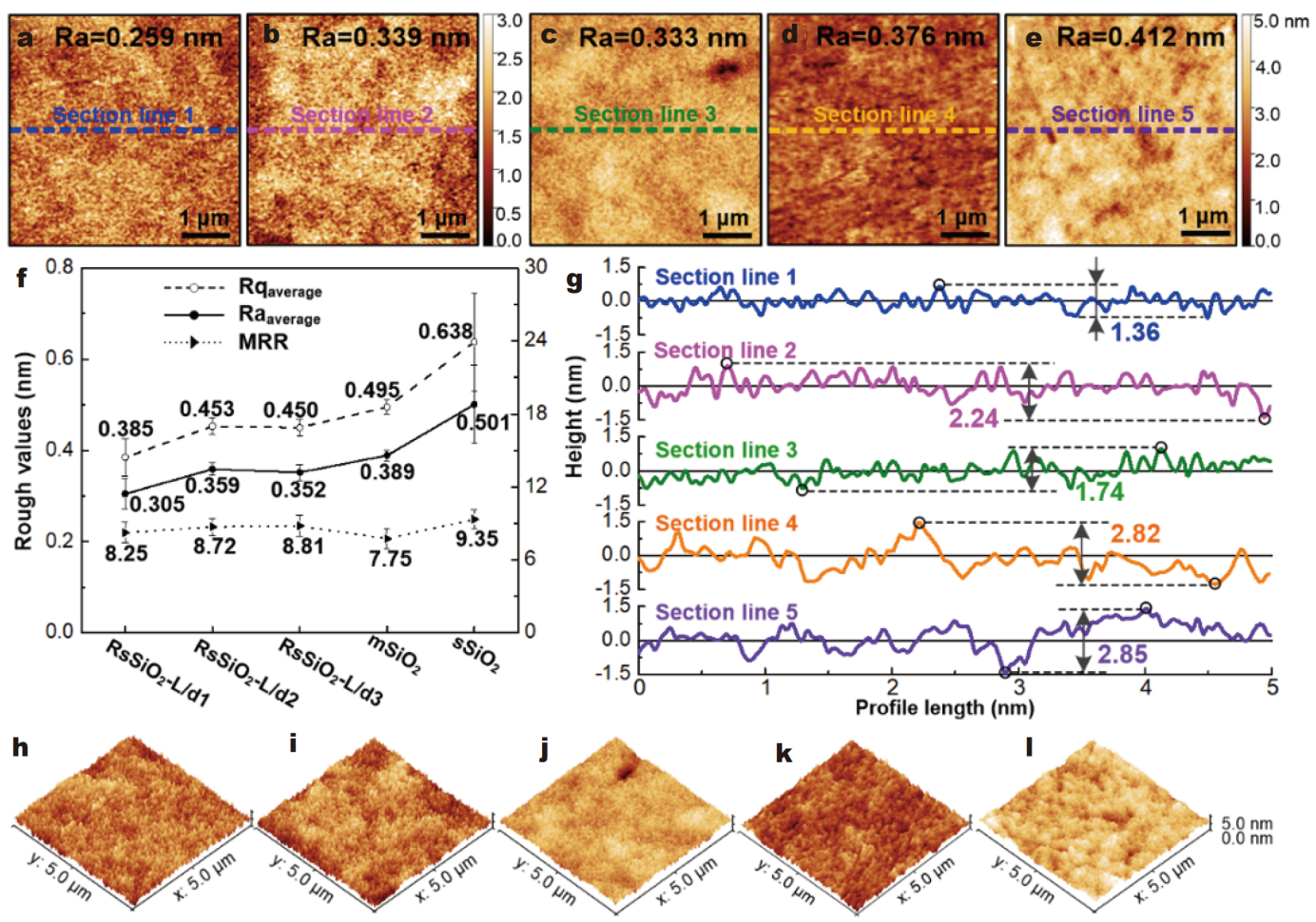

Figure 5 AFM 2D images (a-e) and corresponding 3D images (h-l) of CZT wafers polished with different abrasives: (a, h) $\mathrm{RmSiO}_{2}-1$; $(\mathrm{b}, \mathrm{i}) \mathrm{RmSiO}_{2}-$ 2; (c, j) $\mathrm{RmSiO}_{2}-3$; (d, k) $\mathrm{mSiO}_{2}$; (e, l) $\mathrm{sSiO}_{2}$. (f) Rough values of polished CZT wafers and (g) height comparison of section lines.

abrasives. Therefore, due to the non-rigid character, porous abrasives will deform elastically in the interfacial contact process between the polishing pad and CZT wafers, compared with $\mathrm{sSiO}_{2}$ spheres when loads are applied. The elastic deformation of porous abrasives could reduce the plough behavior of abrasives to wafers, contributing to surface planarization and damage elimination. Thus, it can be explained reasonably that the polishing qualities of $\mathrm{CZT}_{\mathrm{R} 1}, \mathrm{CZT}_{\mathrm{R} 2}, \mathrm{CZT}_{\mathrm{R} 3}$, and $\mathrm{CZT}_{\mathrm{m}}$ are better than that of $\mathrm{CZT}_{\mathrm{s}}$ wafers.

In addition, the most smooth and non-destructive surface obtained by $\mathrm{RmSiO}_{2}-1$ rather than $\mathrm{RmSiO}_{2}-2$ and $\mathrm{RmSiO}_{2}-3$ can also be interpreted by this elastic deformation mechanism from the interfacial contact area. HRSEM, XRD and $\mathrm{N}_{2}$ adsorption/desorption isotherm measurements further verified that the $\mathrm{RmSiO}_{2}$ particles with different $L / d$ ratios have diverse pore frameworks. Moreover, it was verified that the $E$ value of $\mathrm{RmSiO}_{2}-1$ abrasives is the lowest because of their well-ordered and abundant porous structure through modulus measurements. On the basis of elastic micro-contact mechanics, the furthest deformation of $\mathrm{RmSiO}_{2}-1$ will occur among the $\mathrm{RmSiO}_{2}$ when loading pressure because of its smallest $E$ values. Therefore, the indentation and penetration depths also diminish accordingly, inducing low surface defects and high quality. Furthermore, both the smaller size and compacter porous structure of $\mathrm{RmSiO}_{2}-1$ decrease the density per single particle, and thus the total number of $\mathrm{RmSiO}_{2}-1$ particles between the contact of CZT wafers and polishing pad will increase with the constant abrasive solid content in polishing slurry. A large number of active $\mathrm{RmSiO}_{2}-1$ particles play a dominant role in dispersing pressure even the contact area of single large-sized $\mathrm{RmSiO}_{2}-2$ or $\mathrm{RmSiO}_{2}-3$ particles is much larger with wafers. Therefore, the pressure per particle loaded on $\mathrm{RmSiO}_{2}-1$ is much lower than that polished with $\mathrm{RmSiO}_{2}-2$, and $\mathrm{RmSiO}_{2}-3$. This is another reason for indentation reduction and surface planarization on $\mathrm{CZT}_{\mathrm{R} 1}$ wafers. As discussed above, compared with $\mathrm{RmSiO}_{2}-2$ and $\mathrm{RmSiO}_{2}-3, \mathrm{RmSiO}_{2}-1$ with abundant pores is more elastic and softer, contributing to lower topography variations and flatter surface.

Moreover, MD simulation results provided insightful evidence that the movement pattern of ellipsoidal shaped abrasives will transform from rolling to sliding with increasing $L / D$ ratio, which contributes to the reduction of surface defects (e.g., groove depth, dislocation length) $[26,27]$. For $\mathrm{RmSiO}_{2}$ abrasives, these particles are at- 
tempted to slide between the CZT wafers and polishing pad because of their well-designed rod shape. As a result, the sliding probability of $\mathrm{RmSiO}_{2}-3$ abrasives was maximum, while $\mathrm{mSiO}_{2}$ abrasives tend to adopt the rolling behavior with generating pits and ravines. Probably, this can explain why $\mathrm{RmSiO}_{2}$ abrasives achieve more precision machining than $\mathrm{mSiO}_{2}$ ones.

Furthermore, the used $\mathrm{RmSiO}_{2}-1$ abrasives $\left(\mathrm{RmSiO}_{2}-1\right.$ used) were characterized to speculate the deformation of abrasives after the CMP process. The morphology and porous information of $\mathrm{RmSiO}_{2}-1$ abrasives before and after the CMP process are shown in Fig. 6. The TEM and SEM images (Fig. 6a, b, e, f) show that some impurities, dirtiness and fragments appear over the $\mathrm{RmSiO}_{2}$-1-used abrasives with a few broken particles. More obviously, the diameter of abrasives became smaller (loss of 16\%) and the length became shorter (loss of 10\%) after the CMP process. Primarily, the change of dimensions can indicate the abrasives deform and wear away under the action of applied forces. Once the force beyonds the maximum loading, the deformation mode of particles will change from elastic to plastic with the formation of the fragmentation. Secondly, the dimension reduction in diameter direction is visibly higher than that in length direction, implying the dominating stress-bearing surface of abrasives is their largest cylindrical surface. However, for spherical $\mathrm{mSiO}_{2}$ abrasives, the force and pressure are always applied at a random point on their spherical surface. Compared with a large area of stress-bearing surface, the contact mode by point is more inclined to generate pits and scratches, which is not conducive to surface planarization. This is the reason why $\mathrm{RmSiO}_{2}$ abrasives realize more precision machining than $\mathrm{mSiO}_{2}$ abrasives even though they have the similar mesoporous structure.

Additionally, the pore nature of $\mathrm{RmSiO}_{2}-1$ and $\mathrm{RmSiO}_{2}$-1-used abrasives was also characterized. The small-angle XRD patterns (Fig. 6k) suggest that the peak intensity of $\mathrm{RmSiO}_{2}$-1-used abrasives becomes weaker than that of the $\mathrm{RmSiO}_{2}-1$ abrasives. This demonstrates their order degree of mesostructure decreases during the CMP process, which may result from the collapse and destruction of dense porous structure on $\mathrm{RmSiO}_{2}-1$ abrasive surface. Due to the channel collapse, the pores expand and the number of pores with larger diameter increases as demonstrated in Fig. 61 (inset). For this reason, although the average pore diameters of $\mathrm{RmSiO}_{2}-1$ and $\mathrm{RmSiO}_{2}$-1-used abrasives are both about $2.4 \mathrm{~nm}$, the surface area of $\mathrm{RmSiO}_{2}-1$-used abrasives is $934 \mathrm{~m}^{2} \mathrm{~g}^{-1}$, which is slightly lower than that of $\mathrm{RmSiO}_{2}-1$ abrasives $\left(1066 \mathrm{~m}^{2} \mathrm{~g}^{-1}\right)$. The variation of the pore character manifests the significant role of mesoporous structure in alleviation of external pressure to CZT wafers by means of self-disintegration.
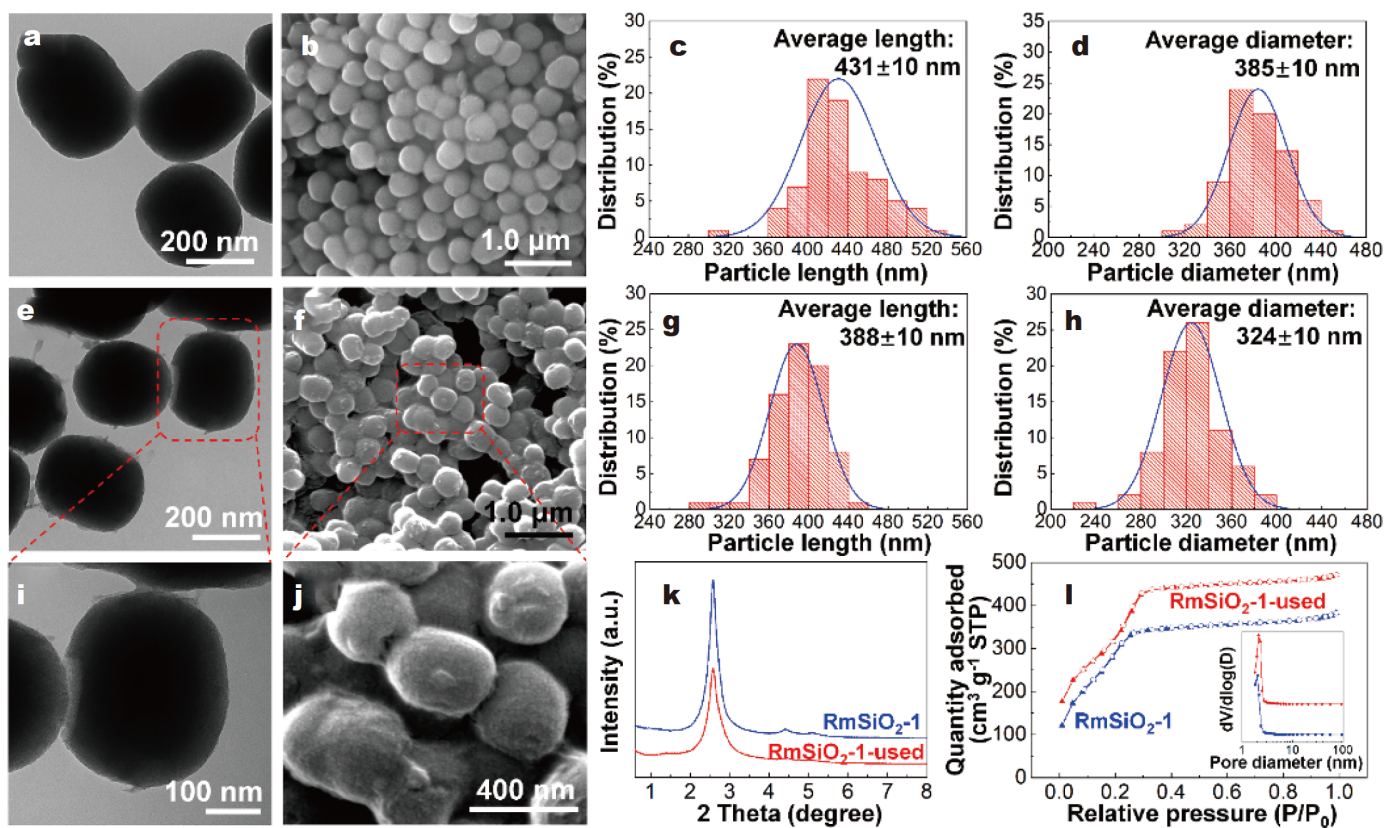

Figure 6 (a) TEM and (b) SEM images of $\mathrm{RmSiO}_{2}-1$ abrasives and their (c) length and (d) diameter distributions. (d) TEM image, (e) SEM image, the corresponding magnifed (i) TEM and (g) SEM images of $\mathrm{RmSiO}_{2}$-1-used abrasives, and their (g) length and (h) diameter distributions. (k) Powder small-angle XRD patterns and (l) $\mathrm{N}_{2}$ adsorption/desorption isotherms of $\mathrm{RmSiO}_{2}$ and $\mathrm{RmSiO}_{2}-1$-used abrasives. 
Another critical index for CMP performance is the polishing efficiency, which can be digitized to MRR. The MRRs of $\mathrm{CZT}_{\mathrm{R} 1}, \mathrm{CZT}_{\mathrm{R} 2}, \mathrm{CZT}_{\mathrm{R} 3}, \mathrm{CZT}_{\mathrm{m}}$, and $\mathrm{CZT}_{\mathrm{s}}$ wafers are determined as $8.25 \pm 0.84,8.72 \pm 0.71,8.81 \pm 0.86$, $7.52 \pm 0.84$, and $9.35 \pm 0.78 \mu \mathrm{m} \mathrm{min}^{-1}$, respectively. It can be concluded that the $\mathrm{sSiO}_{2}$ spheres achieve the highest efficiency, but just a little higher in the removal of CZT than $\mathrm{RmSiO}_{2}$ abrasives in the CMP process, and the removal rate of $\mathrm{mSiO}_{2}$ is the lowest. For $\mathrm{RmSiO}_{2}$ abrasives, the calculated MRR results indicate the polishing efficiency of $\mathrm{RmSiO}_{2}-1$ is slightly low, and the polishing speed of the most efficient $\mathrm{RmSiO}_{2}-3$ is just a little higher than that of $\mathrm{RmSiO}_{2}-2$. The reasons for this are complicated and can be explained legitimately by the following four theories.

Above all, contact area-based models were proposed in the literature and recognized extensively $[62,63]$. Chen et al. [20] investigated the abrasives' mechanical wear effect for material removal in the CMP process, and Equation (2) calculating the MRR in contact state is provided as follows:

$\mathrm{MRR}_{\text {contact }}=d \delta U$,

where $d$ is the actual contact radius of abrasives, $\delta$ is the penetration depth and $U$ is the rotation speed of polishing pad. As presented in the equation, the MRR is in direct proportion to $d$ and $\delta$ when $U$ is kept as a constant. Due to the rigid nature, $\mathrm{sSiO}_{2}$ spheres scarcely deform when they are in contact with $\mathrm{CZT}$ wafers, while $\mathrm{RmSiO}_{2}-2$ and $\mathrm{RmSiO}_{2}-3$ abrasives will perform low elasticity deformation. Their $d$ and $\delta$ values are both larger than those of $\mathrm{RmSiO}_{2}-1$ abrasives, and acorrespondingly their polishing speed is higher than that of $\mathrm{RmSiO}_{2}-1$ and the efficiency of $\mathrm{sSiO}_{2}$ is the highest deservedly because of its lowest $E$. In addition, the actual contact area between the abrasives and CZT wafers can directly affect the MRR, too. The contact area of $\mathrm{RmSiO}_{2}-2$ and $\mathrm{RmSiO}_{2}-3$ increases inevitably with their larger size compared with $\mathrm{RmSiO}_{2}-1$, and that of $\mathrm{RmSiO}_{2}-3$ is the largest because of its micron size. This is the reason why $\mathrm{RmSiO}_{2}-3$ is the most efficient abrasive. The evidence is that the polishing speed of $\mathrm{RmSiO}_{2}-1$ towers over the speed of $\mathrm{mSiO}_{2}$ even though they have a similar size and porous structure. Furthermore, we know that the distinction of the contact mode causes this speed difference. $\mathrm{RmSiO}_{2}-1$ abrasives realize the material removal through line contact with $\mathrm{CZT}$ wafers, while the contact manner of $\mathrm{mSiO}_{2}$ is the point due to its spherical shape. Then, driven by the flowing slurry, the abrasives would move and rotate, resulting in the actual contact area of $\mathrm{RmSiO}_{2}-1$ and $\mathrm{mSiO}_{2}$ changing into a $2 \mathrm{D}$ surface and $1 \mathrm{D}$ line, respectively. The difference in contact area leads $\mathrm{RmSiO}_{2}-1$ abrasives to achieve higher efficiency than $\mathrm{mSiO}_{2}$. Moreover, the transition from sliding to rolling would decrease the friction coefficient of abrasives dramatically. Therefore, the friction force of $\mathrm{mSiO}_{2}$ abrasives was lower than that of $\mathrm{RmSiO}_{2}$ ones with the fixed stress. Accordingly, the less material removal amount per unit time of $\mathrm{mSiO}_{2}$ abrasives results in their poor polishing speed. Moreover, the friction diagram between ellipsoidal abrasives and substrates proposed by Dong et al. [25] also verifies it.

Furthermore, compared with $\mathrm{sSiO}_{2}$ abrasives, the $\mathrm{RmSiO}_{2}-1$ shows a mesoporous structure that is conductive to raising its polishing speed. It was reported that porous abrasives present a special removal mechanism for materials, which is mainly related to their pore size and structure. For example, Chen et al. [64] uncovered the mechanical effect of porous silica clusters on substrates and their pore size-dependent polishing behavior by means of MD simulations. The results revealed that the high MRR is caused by the combined effect of the plough, adhesion, and permeation of clusters to substrate atoms. The adhesion effect plays a dominant role in material removal. It is worth mentioning that the enlarged pore size of clusters will result in increasing active contact area and enhanced adhesion of the pore to substrate atoms. Thus it is easier for abrasives with large-sized pores to pull off the polished material. For the as-synthesized abrasives, $\mathrm{RmSiO}_{2}-1$ has more large-sized pores than $\mathrm{RmSiO}_{2}-2$ and $\mathrm{RmSiO}_{2}-3$ quantitatively, which was confirmed by $\mathrm{BJH}$ pore diameter distributions. Therefore, the large number of expanding pores on the $\mathrm{RmSiO}_{2}-1$ surface facilitates the adhesion and pulling effects of abrasives to CZT wafers, eventually leading to relatively not too low MRR.

Furthermore, Mo et al. [52] hold the view that elastic deformation also results in the adhesion effect, and plays a significant role in friction wear at the nanoscale. This theory is also in favor of understanding why the MRR of $\mathrm{RmSiO}_{2}-1$ is not too low. It is all because of its highest $E$.

Last but not least, as we know, the CMP performance depends on the balance between chemical and mechanical effects. For a chemical reaction, Qi et al. [65] reported that mesoporous abrasives can store water in their micropores, increasing their chemical activity in the CMP process. According to the $\mathrm{BJH}$ pore volume results, the $\mathrm{RmSiO}_{2}-1$ has the largest pore volumes due to its abundant micropores. Therefore, the $\mathrm{RmSiO}_{2}-1$ presents a strong slurry storage capacity, which contributes to an active tribo-chemical reaction. This may be the other 
reason that the MRR of $\mathrm{RmSiO}_{2}-1$ is slightly lower than those of $\mathrm{RmSiO}_{2}-2$ and $\mathrm{RmSiO}_{2}-3$. Moreover, the contact angle measurement (Fig. S6) also provides powerful evidence that $\mathrm{RmSiO}_{2}-1$ is more hydrophilic, which will result in better dispersibility and polishing efficiency.

For evaluating the CMP stability of $\mathrm{RmSiO}_{2}$ abrasives, the identical CMP experiments with the $\mathrm{RmSiO}_{2}-1$ were performed three times as shown in Fig. S7. The 2D and 3D images (Fig. S7a-h) present that the CZT wafers after the identical CMP tests present the same relatively homogeneous color distribution with the original CMP results. Moreover, the corresponding $R a$ values calculated by their height data of CZT wafers after the $1^{\text {st }}, 2^{\text {nd }}$, and $3^{\text {rd }}$ repeated test are $0.231,0.226$, and $0.194 \mathrm{~nm}$, respectively, which are even lower than the original $R a$ values. Moreover, the $R a_{\text {average }}, R q_{\text {average, }}$ and the peak-to-valley values of section lines derived from AFM 2D images all keep nearly the same variation trend with the lowest $R a$ values. This demonstrates that the $\mathrm{RmSiO}_{2}-1$ abrasives can keep the ultra-precision machining ability steadily. Besides, the polishing speed of the repeated tests are 7.98 $\pm 0.83,8.05 \pm 0.86$, and $7.90 \pm 0.89 \mu \mathrm{m} \mathrm{min}^{-1}$, respectively, which are broadly in line with the original MRR value. Therefore, it can be considered that the CMP performance achieved by $\mathrm{RmSiO}_{2}$ abrasives is stable with valuable practical application.

\section{Interfacial mechanochemistry in CMP process}

It is well known that the ultra-precision surface machining with high efficiency in CMP process is achieved through a synergistic effect of chemical corrosion and mechanical removal. Moreover, the speculation that the chemical reactivity is induced or driven by mechanical behavior mainly in the form of force, kinetic energy, and frictional heating becomes increasingly acknowledged in mechanochemical reactions [66-68]. On the one hand, the solid substrate subjected to mechanical stress could initiate the irreversible plastic deformations of convexes on its surface, such as shearing and twisting, and convert to kinetic energy. This will result in structural collision and morphology transition of solid materials. On the other hand, the mechanical kinetic energy could generate plentiful friction heating to accelerate the molecular movement and induce the chemical reaction $[69,70]$. Similarly, this mechanochemical mechanism also applies to the CMP process. For example, as previously reported by utilizing MD simulation, the oxidation of the substrate surface is mechanically induced at the friction interface [23]. The mechanical shearing and sliding behavior of abrasive grain play a key role in the intrusion of $\mathrm{O}$ atoms and raising of the substrate atoms, ultimately resulting in dissociation of surface chemical bonds. Therefore, we ratiocinate boldly that the chemical corrosion in the CMP process can be mechanically induced by importing frictional momentum and heating of abrasives.

With the sustaining input of mechanical energy, chemical compositions in slurry are activated and the chemical reactions between slurry and substrates proceed spontaneously. After being modified by slurry, the substrate will present an easy-to-remove state, which is in favor of achieving surface planarization. Therefore, besides the mechanical character of abrasives, the chemical properties of slurry are equally crucial to CMP performances. It is necessary to figure out the chemical effect of each composition in slurry and further reveal the chemical reaction on interface contacts.

Primarily, electrochemical tests were performed to analyze the CZT corrosion rates of the polishing slurry. The corrosion rate can be evaluated by passivation current density calculated from Tafel polarization curves (Fig. S8). The smaller density signifies the test solution with higher corrosivity to CZT substrates. According to the calculated results, PEG2000 solution has the lowest passivation current density, followed by $\mathrm{H}_{2} \mathrm{O}_{2}, \mathrm{SiO}_{2}$, TA solution, and the polishing slurry has the highest value. The CZT corrosion rate of PEG2000 is even lower than that of $\mathrm{SiO}_{2}$, which indicates that PEG2000 has no erosive attack on CZT substrates during the CMP process. Moreover, it is interesting to note that $\mathrm{H}_{2} \mathrm{O}_{2}$, a typical oxidizing agent, exhibits much lower corrosive speed. This is because the corrosivity of $\mathrm{H}_{2} \mathrm{O}_{2}$ is so strong that a dense oxidation layer would be formed immediately to obstruct the charge exchange once dipping the CZT substrate into the $\mathrm{H}_{2} \mathrm{O}_{2}$ solution. Therefore, the $\mathrm{H}_{2} \mathrm{O}_{2}$ among these ingredients still acts as an oxidizing agent to corrode the CZT surface in spite of its small current density. However, the corrosion rate of polishing slurry including $\mathrm{H}_{2} \mathrm{O}_{2}$ is not affected by its strong oxidizability and remains high. This is because that the TA plays an etching role. As long as the oxidation layer is formed, the $\mathrm{H}^{+}$ionized by TA would react with metallic oxide and collaborate with abrasives to achieve the removal of the oxidation layer integrally and make the new flat CZT surface exposed. Thus, TA can be regarded as a $\mathrm{pH}$ adjuster to provide an acidic environment for easier mechanical removal of the oxide layer. Moreover, the Tafel polarization curve of TA is similar to that of the polishing slurry, which confirms TA has a promoted effect on CZT corrosion.

In order to further characterize the chemical properties 
of polishing slurry, the XPS spectra were scanned to detect the chemical states of $\mathrm{Te}, \mathrm{Cd}$, and $\mathrm{O}$ elements on the CZT wafer surface. The amount of Zn element is too little to monitor, and thus its analysis was neglected. The XPS spectra of the CZT substrate after lapping and polishing are shown in Fig. 7. The core level peak near $572 \mathrm{eV}$ has been identified as the $\mathrm{Te}^{2-}$ ions in the CZT with a perfect zincblende structure [71]. Thus, the peaks located at $572.2 \mathrm{eV}$ are attributed to $\mathrm{Te}-\mathrm{Cd}$ or $\mathrm{Te}-\mathrm{Zn}$ bonds in CZT. Moreover, another component peak at $572.9 \mathrm{eV}$ in the spectrum of polished CZT can be ascribed to $\mathrm{Te}^{0} 3 \mathrm{~d}_{5 / 2}$ for the metallic state, while the peak at $572.4 \mathrm{eV}$ in the spectrum of CZT after lapping represents Te with a certain valence state between 0 and -2 , which may be caused by slight oxidation in the high-speed lapping process. In addition to this, the peak located at $575.8 \mathrm{eV}$ can be ascribed to $\mathrm{Te}^{4+}-\mathrm{O}$ bonds in tellurium compounds such as $\mathrm{TeO}_{2}, \mathrm{TeO}_{3}{ }^{2-}$, and $\mathrm{Te}_{2} \mathrm{O}_{5}{ }^{2-}$. It is well known that atoms at higher oxidation states will exhibit higher binding energy [72], so the individual small peak at $576.9 \mathrm{eV}$ in the spectrum of polished CZT can be assigned to $\mathrm{Te}^{6+}-\mathrm{O}$ bonds with a higher valence state. Comparing the $\mathrm{Te} 3 \mathrm{~d}_{5 / 2}$ spectra of CZT before and after lapping and polishing, it can be noted that the peaks attributed to $\mathrm{Te}^{4+}-\mathrm{O}$ bonds become significantly stronger and the peaks accredited to the low valence state become weaker. Moreover, the spectrum of polished CZT exhibits a small peak with a high valence state. All of this is because that CZT wafers are oxidized by $\mathrm{H}_{2} \mathrm{O}_{2}$ after CMP. The reactive Equations (3)-(5) of $\mathrm{H}_{2} \mathrm{O}_{2}$ solution on CZT wafer surface are proposed as followed:

$2 \mathrm{Cd}_{0.96} \mathrm{Zn}_{0.04} \mathrm{Te}$ (surface) $+4 \mathrm{H}_{2} \mathrm{O}_{2} \rightleftharpoons$

$1.92 \mathrm{CdO}+0.08 \mathrm{ZnO}+\mathrm{Te}+\mathrm{TeO}_{2}+4 \mathrm{H}_{2} \mathrm{O}$,

$3 \mathrm{Te}+6 \mathrm{H}_{2} \mathrm{O}_{2} \rightleftharpoons \mathrm{H}_{2} \mathrm{TeO}_{3}+\mathrm{H}_{2} \mathrm{Te}_{2} \mathrm{O}_{5}+4 \mathrm{H}_{2} \mathrm{O}$,
$\mathrm{TeO}_{2}+\mathrm{H}_{2} \mathrm{O}_{2}+2 \mathrm{H}_{2} \mathrm{O} \rightleftharpoons \mathrm{H}_{6} \mathrm{TeO}_{6}$.

For $\mathrm{Cd}_{5 / 2}$ spectra of CZT wafers after lapping and polishing (Fig. 7b, e), the peaks located at 404.8 and $404.9 \mathrm{eV}$ can be attributed to Cd linked to Te in CZT and $\mathrm{Cd}-\mathrm{O}$ bonds existing in $\mathrm{CdO}$, respectively. Moreover, the peak intensity in the spectrum of polished CZT is obviously weaker than that of CZT after lapping, which may be caused by TA. After oxidation by $\mathrm{H}_{2} \mathrm{O}_{2}$, the cadmium oxide will be formed in quantity, and the original $\mathrm{Cd}-\mathrm{Te}$ bonds on the CZT surface will be reduced accordingly. However, the $\mathrm{H}^{+}$ionized by TA will react with the basic metal oxides and the generated $\mathrm{Cd}^{2+}$ will be dissolved in the slurry. The relevant chemical reactions are depicted by Equation (6) as below:

$\mathrm{CdO}+\mathrm{ZnO}+4 \mathrm{H}^{+} \rightarrow \mathrm{Cd}^{2+}+\mathrm{Zn}^{2+}+2 \mathrm{H}_{2} \mathrm{O}$.

In addition to this, TA, as one of the natural polyphenols, can be deprotonated and then chelate with metal ions through its rich catechol groups to form metalphenolic complexes $[73,74]$. The chelate of TA with dissociated $\mathrm{Zn}^{2+}$ or $\mathrm{Cd}^{2+}$ in the polishing slurry can be observed in the FTIR spectrum. As shown in Fig. 8a, the emerging adsorption bands at 1715,1196 and $1085 \mathrm{~cm}^{-1}$ in the chelate of TA and CZT (TA-CZT) derive from the stretching vibration of the carbonyl group $(\mathrm{C}=\mathrm{O})$, phenolic hydroxyl group (Ar-OH), and carbon-oxygen bond (C-O) of TA molecule, respectively [75-77]. This substantiates the successful chelation between TA and dissociated metal ions in polishing slurry, which will reduce the direct emission of $\mathrm{Zn}^{2+}$ or $\mathrm{Cd}^{2+}$ and protect the environment. Moreover, their complexation state is in a highly $\mathrm{pH}$-dependent manner [78,79]. Under the acidic polishing condition, one metal ion can only chelate with one catechol group in deprotonated TA, and their chelating interactions are shown in Fig. 8 b.

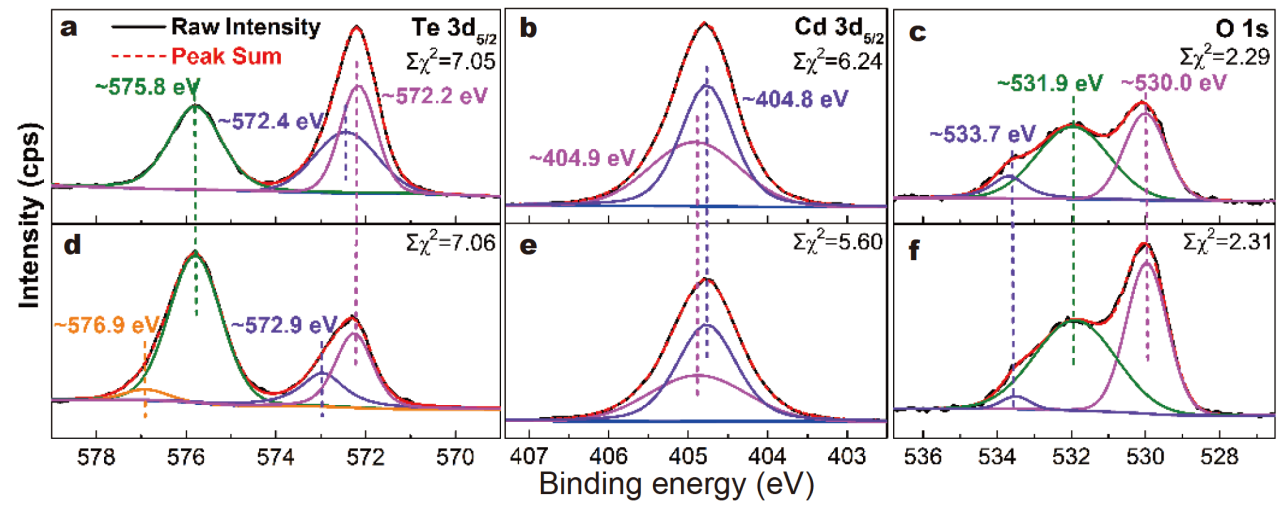

Figure 7 XPS spectra of Te 3d (a, d), Cd 3d (b, e) and O 1s (c, f) core levels on CZT wafers subjected to different treatments: after lapping (a-c), after CMP (d-f). 
Besides, the $\mathrm{O}$ 1s peaks in XPS spectra (Fig. 7c and $\mathrm{f}$ ) are divided into three components located at 530.0, 531.9, and $533.7 \mathrm{eV}$, corresponding to CZT oxide, $\mathrm{C}-\mathrm{O}$ bonds, and loosely adsorbed $\mathrm{H}-\mathrm{O}$ bonds on the CZT surface, respectively. As we can see, the intensities of the former two components are enhanced strongly after CMP. This is most probably because of the adsorption of PEG2000 with long chains of molecules and TA with plentiful hydroxyl groups on the CZT surface.

To further support these inferences about the chemical properties of ingredients in the polishing slurry, XPS spectra of CZT wafers immersed in solutions including different ingredients are recorded in Fig. S9. According to the position and valence state of each component derived from Te $3 d_{5 / 2}$ and $C d 3 d_{5 / 2}$ peaks in Fig. 7 , it can be inferred that the corresponding valence states of components in Fig. S7 have similar positions with them. As observed, the peak of Te $3 \mathrm{~d}_{5 / 2}$ with high oxidant valence state in intensity order from strong to weak belongs to CZT wafers immersed in the polishing slurry, $\mathrm{H}_{2} \mathrm{O}_{2}$, TA, and PEG2000 solutions, respectively. Moreover, the peaks assigned to cadmium oxide in $\mathrm{Cd} 3 \mathrm{~d}_{5 / 2}$ spectra also follow this pattern. This is in line with that $\mathrm{H}_{2} \mathrm{O}_{2}$ exhibits strong corrosivity properties to act as an oxidizing agent in the polishing slurry. For spectra of CZT wafers immersed in the polishing slurry, the peaks accredited to the original CZT state are the weakest, but the peaks ascribed to CZT oxide are not the strongest even though the slurry contains $\mathrm{H}_{2} \mathrm{O}_{2}$. This confirms the previous speculation that the $\mathrm{H}^{+}$ionized by TA will react with CZT oxide and accelerate the oxidation process through the "forming and removing oxide layer" cycle. Furthermore, the weak oxidizing effect can be noticed in the spectra of CZT wafers immersed in TA, indicating that only TA does not play a prominent oxidizing role yet still has a feeble corrosion effect on CZT wafers. The peak attributed to the oxidizing state in spectra of CZT wafer immersed in PEG2000 solution almost has no obvious peak, which corroborates that PEG2000 has no corrosion damage effect on CZT wafers. The PEG2000, a linear polymer with amphiphilic property, is widely used as non-ionic surfactants in foodstuff, cosmetics, and pharmaceutical industries due to its inertness and biocompatible nature. The primary function of PEG2000 in polishing slurry is to utilize its oxygen groups to link to hydroxyl groups on silicon particle surface via hydrogen bonds. After modification with PEG2000, the resultant silica particles will repel each other by steric effects and exhibit excellent colloidal stability [80-82].

Up to this point, the chemical property of every component in the polishing slurry, and the reaction occurring during the CMP process have been discussed and identified. Thereby, the CMP mechanism of the developed polishing slurry containing novel $\mathrm{RmSiO}_{2}$ abrasives to CZT wafers can be elucidated into three steps, as shown in Fig. 9. Originally, with the actuation of the exterior loads and kinetic energy, $\mathrm{RmSiO}_{2}$ abrasives move quickly and rub against CZT substrates, causing the bulge of the impact to collapse and generating frictional heating. This mechanical effect accelerates the molecular motion of chemical components in the slurry and induces a series of following chemical reactions: firstly, $\mathrm{H}_{2} \mathrm{O}_{2}$ solution in the slurry acting as an oxidizing agent will oxide rugged $\mathrm{CZT}$ surface to form a compact oxidized layer. Then, the $\mathrm{H}^{+}$ released by ionization of TA will react with the basic metal oxides such as $\mathrm{CdO}$ and $\mathrm{ZnO}$ into metal ions, causing the removal of the partially oxidized layer. Subsequently, the deprotonated TA molecules chelate with the $\mathrm{Cd}^{2+}$ and $\mathrm{Zn}^{2+}$ to form a catechol- $\mathrm{Cd}^{2+} / \mathrm{Zn}^{2+}$ monocomplex with a stoichiometric ratio of 1:1. Lastly, the complexes are discharged as the flowing polishing slurry. In the end, dispersed $\mathrm{RmSiO}_{2}$ abrasives will deform
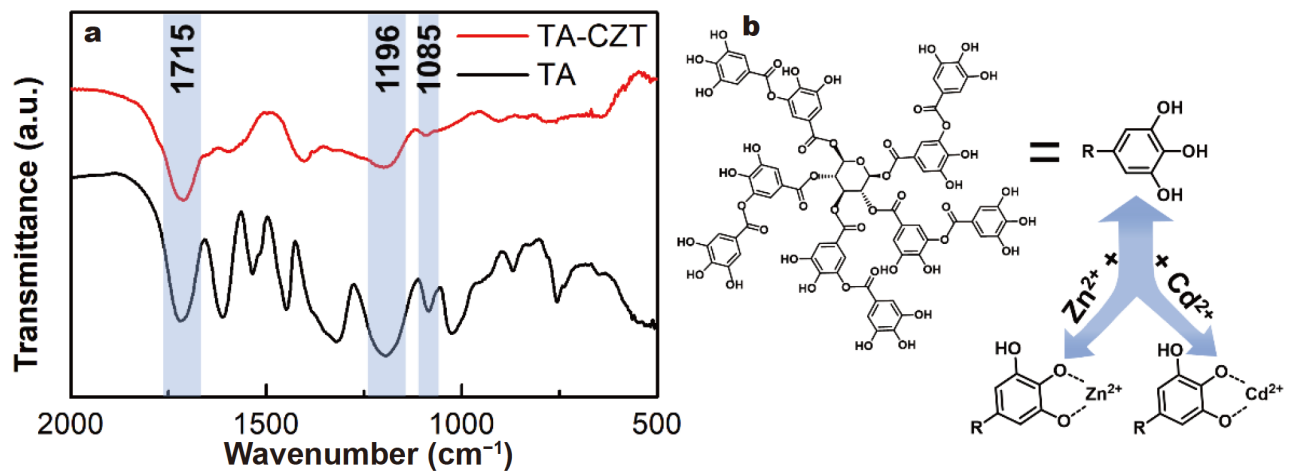

Figure 8 FTIR spectra of TA-CZT and TA (a), the chelating process for catechol- $\mathrm{Cd}^{2+} / \mathrm{Zn}^{2+}$ mono-complex under acid condition (b). 


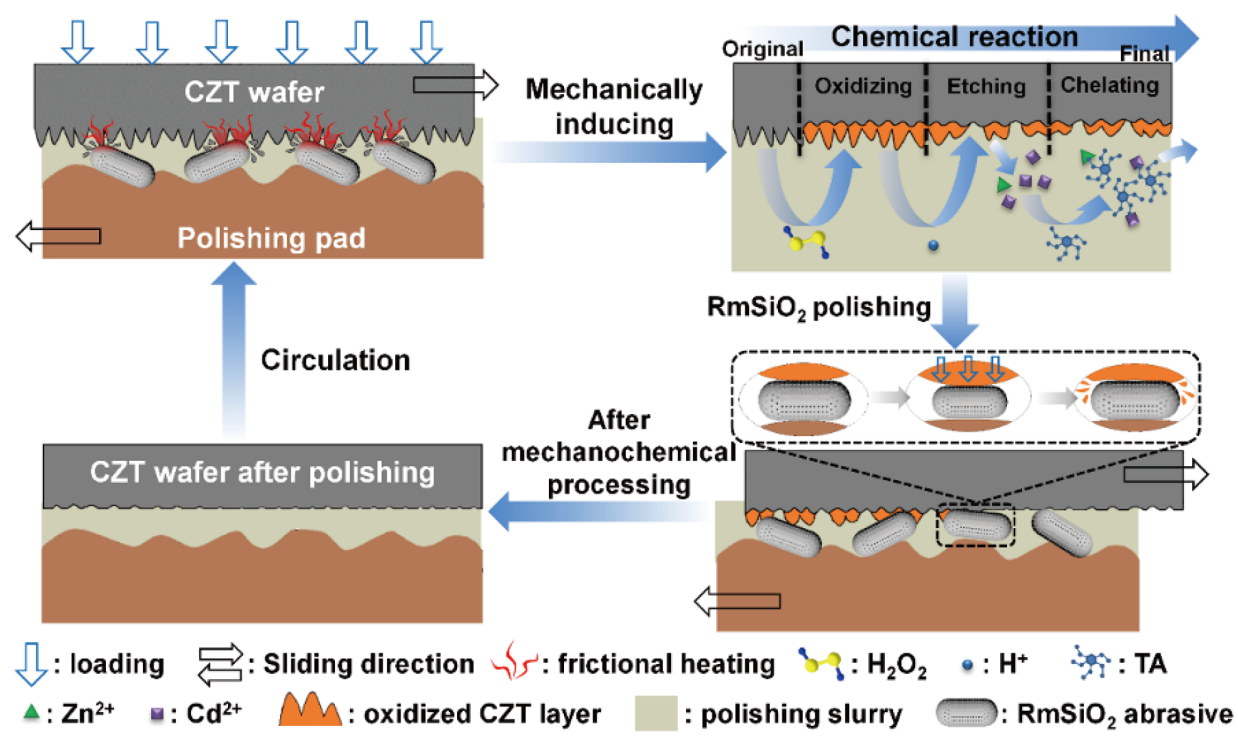

Figure 9 Proposed schematic diagram of CMP mechanism induced by the developed novel slurry.

elastically when subjected to the extrusion of the polishing pad and CZT wafers due to their abundant pores with a well-ordered structure and accurately remove the remaining oxidized layer. The reduction of indentation depth contributes to the formation of a low-defect surface. After several of these CMP cycles, the surface accuracy of CZT wafers achieves the sub-nanometer scale ultimately.

\section{CONCLUSIONS}

In conclusion, an extended Stöber method has been adapted to successfully synthesize a series of non-spherical $\mathrm{RmSiO}_{2}$ particles with controllable sizes and diverse mesostructures, which were eventually applied in a sustainable CMP process on CZT wafers. The polishing results indicate that the non-spherical mesoporous $\mathrm{RmSiO}_{2}$ abrasives can achieve a substantial improvement of surface planarization to soft and brittle materials relative to commercial silica gel, $\mathrm{mSiO}_{2}$ and $\mathrm{sSiO}_{2}$ spheres. Furthermore, on account of the well-ordered and tightly arranged mesoporous structure on $\mathrm{RmSiO}_{2}$ abrasive surface, they have lower $E$ values and deform elastically when loading is applied, which results in the low topographical variation and defect-free surface. Moreover, their specific compact pore structure is prone to generating large-sized pores to adhere to and pull off materials and storage slurry to accelerate the interfacial chemical reactions in the CMP process, which facilitates the improvement of material removal speed. In addition, the rod shape of $\mathrm{RmSiO}_{2}$ can enhance the actual contact area between abrasives and CZT wafers, and increase its friction coefficient by sliding movement, consequently raising the polishing efficiency. Ultimately, the "mechanically inducing-chemical corrosion-mechanical removal" cyclic model is proposed to describe the synergistic mechanochemical effect of mechanical friction from $\mathrm{RmSiO}_{2}$ and chemical corrosion from other compositions in the CMP process. This work reveals a possible CMP mechanism for CZT materials and will provide guidance on precision machining for other key materials and components.

Moreover, as abrasives are the primary participant in mechanical energy transmission and chemical reaction, their physicochemical properties are an important factor in CMP performance. With the increasing demand for more ultra-precision and the more non-damage surface of core materials, it is suggested to optimize the characters of abrasives, such as their morphology, structure, and even surface chemical state. More importantly, the CMP performance could be improved by individually or jointly modifying the abrasive properties. Therefore, it is imperative to propose more synthetic strategies of modified abrasives or novel recipes in polishing slurry to promote the development of CMP technology.

Received 25 March 2021; accepted 29 March 2021; published online 18 June 2021

1 Chappert C, Bernas H, Ferre J, et al. Planar patterned magnetic media obtained by ion irradiation. Science, 1998, 280: 1919-1922

2 Barredo D, Calleja F, Nieto P, et al. A quantum-stabilized mirror 
for atoms. Adv Mater, 2008, 20: 3492-3497

3 Nagpal P, Lindquist NC, Oh SH, et al. Ultrasmooth patterned metals for plasmonics and metamaterials. Science, 2009, 325: 594597

4 Wang C, Fu B, Zhang X, et al. Solution-processed, large-area, twodimensional crystals of organic semiconductors for field-effect transistors and phototransistors. ACS Cent Sci, 2020, 6: 636-652

5 Hou N, Zhang L, Zhang Y, et al. On the ultra-precision fabrication of damage-free optical KDP components: Mechanisms and problems. Critical Rev Solid State Mater Sci, 2019, 44: 283-297

6 Krishnan M, Nalaskowski JW, Cook LM. Chemical mechanical planarization: Slurry chemistry, materials, and mechanisms. Chem Rev, 2010, 110: 178-204

7 DeSimone JM. Practical approaches to green solvents. Science, 2002, 297: 799-803

8 Pai RA, Humayun R, Schulberg MT, et al. Mesoporous silicates prepared using preorganized templates in supercritical fluids. Science, 2004, 303: 507-510

9 Bessel CA, Denison GM, DeSimone JM, et al. Etchant solutions for the removal of $\mathrm{Cu}(0)$ in a supercritical $\mathrm{CO}_{2}$-based "dry" chemical mechanical planarization process for device fabrication. J Am Chem Soc, 2003, 125: 4980-4981

10 Guo D, Liu J, Kang R, et al. A pad roughness model for the analysis of lubrication in the chemical mechanical polishing of a silicon wafer. Semicond Sci Technol, 2007, 22: 793-797

11 Kim H, Hong S, Shin C, et al. Investigation of the pad-conditioning performance deterioration in the chemical mechanical polishing process. Wear, 2017, 392-393: 93-98

12 Thomas ELH, Nelson GW, Mandal S, et al. Chemical mechanical polishing of thin film diamond. Carbon, 2014, 68: 473-479

13 Wang L, Zhou P, Yan Y, et al. Physically-based modeling of padasperity scale chemical-mechanical synergy in chemical mechanical polishing. Tribol Int, 2019, 138: 307-315

14 Liao L, Zhang Z, Liu J, et al. A novel process of chemical mechanical polishing for FV520B steel. J Manuf Proc, 2020, 59: 51-57

15 Werrell JM, Mandal S, Thomas ELH, et al. Effect of slurry composition on the chemical mechanical polishing of thin diamond films. Sci Tech Adv Mater, 2017, 18: 654-663

16 Xie W, Zhang Z, Liao L, et al. Green chemical mechanical polishing of sapphire wafers using a novel slurry. Nanoscale, 2020, 12: 22518-22526

17 Zhang Z, Cui J, Zhang J, et al. Environment friendly chemical mechanical polishing of copper. Appl Surf Sci, 2019, 467-468: 5-11

18 Zhang Z, Liao L, Wang X, et al. Development of a novel chemical mechanical polishing slurry and its polishing mechanisms on a nickel alloy. Appl Surf Sci, 2020, 506: 144670

19 Zhang Z, Wang B, Zhou P, et al. A novel approach of chemical mechanical polishing for cadmium zinc telluride wafers. Sci Rep, 2016, 6: 26891

20 Chen H, Guo D, Xie G, et al. Mechanical model of nanoparticles for material removal in chemical mechanical polishing process. Friction, 2016, 4: 153-164

21 Chen R, Li S, Wang Z, et al. Mechanical model of single abrasive during chemical mechanical polishing: Molecular dynamics simulation. Tribol Int, 2019, 133: 40-46

22 Feng X, Sayle DC, Wang ZL, et al. Converting ceria polyhedral nanoparticles into single-crystal nanospheres. Science, 2006, 312: 1504-1508

23 Kawaguchi K, Ito $\mathrm{H}$, Kuwahara $\mathrm{T}$, et al. Atomistic mechanisms of chemical mechanical polishing of a $\mathrm{Cu}$ surface in aqueous $\mathrm{H}_{2} \mathrm{O}_{2}$ :
Tight-binding quantum chemical molecular dynamics simulations. ACS Appl Mater Interfaces, 2016, 8: 11830-11841

24 Nguyen VT, Fang TH. Molecular dynamics simulation of abrasive characteristics and interfaces in chemical mechanical polishing. Appl Surf Sci, 2020, 509: 144676

25 Dong Y, Lei H, Liu W, et al. Preparation of ellipsoidal rod-shaped silica nanocomposite abrasives by chromium ion/PEG200 induced method for sapphire substrates chemical mechanical polishing. J Alloys Compd, 2019, 777: 1294-1303

26 Fang L, Sun K, Shi J, et al. Movement patterns of ellipsoidal particles with different axial ratios in three-body abrasion of monocrystalline copper: A large scale molecular dynamics study. RSC Adv, 2017, 7: 26790-26800

27 Shi J, Wei X, Chen J, et al. Influence of abrasive shape on the abrasion and phase transformation of monocrystalline silicon. Crystals, 2018, 8: 32

$28 \mathrm{Xu}$ L, Lei H. Nano-scale surface of $\mathrm{ZrO}_{2}$ ceramics achieved efficiently by peanut-shaped and heart-shaped $\mathrm{SiO}_{2}$ abrasives through chemical mechanical polishing. Ceram Int, 2020, 46: 13297-13306

29 Jiang B, Guo Y, Kim J, et al. Mesoporous metallic iridium nanosheets. J Am Chem Soc, 2018, 140: 12434-12441

30 Li W, Elzatahry A, Aldhayan D, et al. Core-shell structured titanium dioxide nanomaterials for solar energy utilization. Chem Soc Rev, 2018, 47: 8203-8237

31 Qiu P, Ma B, Hung CT, et al. Spherical mesoporous materials from single to multilevel architectures. Acc Chem Res, 2019, 52: 29282938

32 Li W, Yang J, Wu Z, et al. A versatile kinetics-controlled coating method to construct uniform porous $\mathrm{TiO}_{2}$ shells for multifunctional core-shell structures. J Am Chem Soc, 2012, 134: 1186411867

33 Li C, Tan H, Lin J, et al. Emerging Pt-based electrocatalysts with highly open nanoarchitectures for boosting oxygen reduction reaction. Nano Today, 2018, 21: 91-105

34 Su H, Tian Q, Hurd Price CA, et al. Nanoporous core@shell particles: Design, preparation, applications in bioadsorption and biocatalysis. Nano Today, 2020, 31: 100834

35 Li C, Iqbal M, Jiang B, et al. Pore-tuning to boost the electrocatalytic activity of polymeric micelle-templated mesoporous $\mathrm{Pd}$ nanoparticles. Chem Sci, 2019, 10: 4054-4061

36 Chen A, Ma X, Cai W, et al. Polystyrene-supported dendritic mesoporous silica hybrid core/shell particles: Controlled synthesis and their pore size-dependent polishing behavior. J Mater Sci, 2020, 55: 577-590

37 Chen $\mathrm{Y}, \mathrm{Mu} \mathrm{Z}$, Wang W, et al. Development of mesoporous $\mathrm{SiO}_{2} /$ $\mathrm{CeO}_{2}$ core/shell nanoparticles with tunable structures for nondamage and efficient polishing. Ceramics Int, 2020, 46: 4670-4678

38 Cheng J, Huang S, Li Y, et al. $\mathrm{Re}\left(\mathrm{La}, \mathrm{Nd}\right.$ and $\mathrm{Yb}$ ) doped $\mathrm{CeO}_{2}$ abrasive particles for chemical mechanical polishing of dielectric materials: Experimental and computational analysis. Appl Surf Sci, 2020, 506: 144668

39 Liu T, Lei $\mathrm{H}$. $\mathrm{Nd}^{3+}$-doped colloidal $\mathrm{SiO}_{2}$ composite abrasives: Synthesis and the effects on chemical mechanical polishing (CMP) performances of sapphire wafers. Appl Surf Sci, 2017, 413: 16-26

40 Pan GS, Gu ZH, Zhou Y, et al. Preparation of silane modified $\mathrm{SiO}_{2}$ abrasive particles and their chemical mechanical polishing (CMP) performances. Wear, 2011, 273: 100-104

41 Zhang $\mathrm{B}$, Lei $\mathrm{H}$, Chen Y. Preparation of $\mathrm{Ag}_{2} \mathrm{O}$ modified silica abrasives and their chemical mechanical polishing performances on sapphire. Friction, 2017, 5: 429-436 
42 Chen A, Chen Y, Zhao X, et al. Core/shell structured $\mathrm{PS} / \mathrm{mSiO}_{2}$ hybrid particles: Controlled preparation, mechanical property, and their size-dependent CMP performance. J Alloys Compd, 2019, 779: $511-520$

43 Chen Y, Li Z, Qin J, et al. Monodispersed mesoporous silica $\left(\mathrm{mSiO}_{2}\right)$ spheres as abrasives for improved chemical mechanical planarization performance. J Mater Sci, 2016, 51: 5811-5822

44 Li C, Iqbal M, Lin J, et al. Electrochemical deposition: An advanced approach for templated synthesis of nanoporous metal architectures. Acc Chem Res, 2018, 51: 1764-1773

45 Chen Y, Zuo C, Ma X, et al. Solid-silica core/mesoporous-silica shell composite abrasives: Synthesis, characterization, and the effect of mesoporous shell structures on CMP. J Mater Sci-Mater Electron, 2017, 29: 3817-3828

46 Huang L, Wang Z, Lei H, et al. Preparation of porous alumina-gpolystyrene sulfonic acid abrasive and its chemical mechanical polishing behavior on hard disk substrate. Microelectron Eng, 2014, 116: 11-16

47 Lei H, Wu X, Chen R. Preparation of porous alumina abrasives and their chemical mechanical polishing behavior. Thin Solid Films, 2012, 520: 2868-2872

48 Cao X, Pan G, Huang P, et al. Silica-coated core-shell structured polystyrene nanospheres and their size-dependent mechanical properties. Langmuir, 2017, 33: 8225-8232

49 Chen A, Qian C, Chen Y, et al. Exploring the elastic behavior of core-shell organic-inorganic spherical particles by AFM indentation experiments. J Inorg Organomet Polym, 2014, 24: 1070-1076

50 Chen Y, Qian C, Miao N. Atomic force microscopy indentation to determine mechanical property for polystyrene-silica core-shell hybrid particles with controlled shell thickness. Thin Solid Films, 2015, 579: 57-63

51 Jauffrès D, Yacou C, Verdier M, et al. Mechanical properties of hierarchical porous silica thin films: Experimental characterization by nanoindentation and finite element modeling. Microporous Mesoporous Mater, 2011, 140: 120-129

52 Mo Y, Turner KT, Szlufarska I. Friction laws at the nanoscale. Nature, 2009, 457: 1116-1119

53 Androulakis J, Peter SC, Li H, et al. Dimensional reduction: A design tool for new radiation detection materials. Adv Mater, 2011, 23: $4163-4167$

54 Cohen-Taguri G, Sinkevich O, Levinshtein $\mathrm{M}$, et al. Atomic structure and electrical properties of $\operatorname{In}(\mathrm{Te})$ nanocontacts on $\mathrm{CdZnTe}(110)$ by scanning probe microscopy. Adv Funct Mater, 2010, 20: 215-223

55 Schlesinger TE, Toney JE, Yoon $\mathrm{H}$, et al. Cadmium zinc telluride and its use as a nuclear radiation detector material. Mater Sci EngR-Rep, 2001, 32: 103-189

56 Wei H, Huang J. Halide lead perovskites for ionizing radiation detection. Nat Commun, 2019, 10: 1066

57 Chen A, Wang W, Ma X, et al. Ceria coated hexagonal mesoporous silica core-shell composite particle abrasives for improved chemical-mechanical planarization performance. J Porous Mater, 2019, 26: 1005-1015

58 Wan Y, Zhao D. On the controllable soft-templating approach to mesoporous silicates. Chem Rev, 2007, 107: 2821-2860

59 García-Uriostegui L, Meléndez-Ortiz HI, Toriz G, et al. Postgrafting and characterization of mesoporous silica MCM- 41 with a thermoresponsive polymer TEVS/NIPAAm/ $\beta$-cyclodextrin. Mater Lett, 2017, 196: 26-29

60 Tan B, Lehmler HJ, Vyas SM, et al. Controlling nanopore size and shape by fluorosurfactant templating of silica. Chem Mater, 2005, 17: 916-925

61 Chu H, Wan Y, Zhao D. Synthesis of Ti-containing mesoporous silicates from inorganic titanium sources. Catal Today, 2009, 148: $19-27$

62 Bozkaya D, Muftu S. Effects of surface forces on material removal rate in chemical mechanical planarization. J Electrochem Soc, 2010, 157: H287

63 Chen X, Zhao Y, Wang Y. Modeling the effects of particle deformation in chemical mechanical polishing. Appl Surf Sci, 2012, 258: 8469-8474

64 Chen R, Jiang R, Lei H, et al. Material removal mechanism during porous silica cluster impact on crystalsilicon substrate studied by molecular dynamics simulation. Appl Surf Sci, 2013, 264: 148-156

65 Qi Y, Chen L, Jiang S, et al. Investigation of silicon wear against non-porous and micro-porous $\mathrm{SiO}_{2}$ spheres in water and in humid air. RSC Adv, 2016, 6: 89627-89634

66 Do JL, Friščić T. Chemistry 2.0: Developing a new, solvent-free system of chemical synthesis based on mechanochemistry. Synlett, 2017, 28: 2066-2092

67 Michalchuk AAL, Hope KS, Kennedy SR, et al. Ball-free mechanochemistry: In situ real-time monitoring of pharmaceutical cocrystal formation by resonant acoustic mixing. Chem Commun, 2018, 54: 4033-4036

68 Tireli M, Juribašić Kulcsár M, Cindro N, et al. Mechanochemical reactions studied by in situ Raman spectroscopy: Base catalysis in liquid-assisted grinding. Chem Commun, 2015, 51: 8058-8061

69 Singh NK, Hardi M, Balema VP. Mechanochemical synthesis of an yttrium based metal-organic framework. Chem Commun, 2013, 49: 972-974

70 Užarević K, Halasz I, Friščić T. Real-time and in situ monitoring of mechanochemical reactions: A new playground for all chemists. J Phys Chem Lett, 2015, 6: 4129-4140

71 Shen $\mathrm{Y}, \mathrm{Xu} \mathrm{Y}$, Sun J, et al. Interface regulation and photoelectric performance of CdZnTe/AlN composite structure for UV photodetector. Surf Coatings Tech, 2019, 358: 900-906

72 Waldiya M, Bhagat D, Mukhopadhyay I. Photoelectrochemical study of electrochemically synthesized CdTe thin films from acetate-anion based ionic liquid bath. Electrochim Acta, 2020, 331: 135437

73 Wei J, Wang G, Chen F, et al. Sol-gel synthesis of metal-phenolic coordination spheres and their derived carbon composites. Angew Chem Int Ed, 2018, 57: 9838-9843

74 Zhang X, Huang L, Wang Q, et al. Transformation of homobimetallic MOFs into nickel-cobalt phosphide/nitrogen-doped carbon polyhedral nanocages for efficient oxygen evolution electrocatalysis. J Mater Chem A, 2017, 5: 18839-18844

75 Sun Y, Shi J, Zhang S, et al. Hierarchically porous and watertolerant metal-organic frameworks for enzyme encapsulation. Ind Eng Chem Res, 2019, 58: 12835-12844

76 Zhu W, Li X, Sun Y, et al. Introducing hydrophilic ultra-thin ZIF-L into mixed matrix membranes for $\mathrm{CO}_{2} / \mathrm{CH}_{4}$ separation. RSC Adv, 2019, 9: 23390-23399

77 Huang Y, Fang Y, Lu XF, et al. $\mathrm{Co}_{3} \mathrm{O}_{4}$ hollow nanoparticles embedded in mesoporous walls of carbon nanoboxes for efficient lithium storage. Angew Chem Int Ed, 2020, 59: 19914-19918

78 Ejima H, Richardson JJ, Liang K, et al. One-step assembly of coordination complexes for versatile film and particle engineering. Science, 2013, 341: 154-157

79 Wei J, Liang Y, Hu Y, et al. Hydrothermal synthesis of metal- 
polyphenol coordination crystals and their derived metal/N-doped carbon composites for oxygen electrocatalysis. Angew Chem Int Ed, 2016, 55: 12470-12474

80 Sperling RA, Parak WJ. Surface modification, functionalization and bioconjugation of colloidal inorganic nanoparticles. Phil Trans R Soc A, 2010, 368: 1333-1383

81 Zhao L, Yuan W, Ang CY, et al. Silica-polymer hybrid with selfassembled PEG corona excreted rapidly via a hepatobiliary route. Adv Funct Mater, 2016, 26: 3036-3047

82 Guo X, Mao T, Wang Z, et al. Fabrication of photoresponsive crystalline artificial muscles based on PEGylated covalent organic framework membranes. ACS Cent Sci, 2020, 6: 787-794

Acknowledgements This work was supported by the National Key R\&D Program of China (2018YFA0703400), the Xinghai Science Funds for Distinguished Young Scholars and Thousand Youth Talents at Dalian University of Technology, the Collaborative Innovation Center of Major Machine Manufacturing in Liaoning, Liaoning BaiQianWan Talents Program, and Dalian National Laboratory for Clean Energy (DNL), DNL Cooperation Fund, Chinese Academy of Sciences (DNL180402). The authors thank Xinyao Wang for her suggestions on figure processing.

Author contributions Zhang Z and Liu J conceived this project. Liu T guided the experiments. Gao $\mathrm{P}$ and Meng F performed the experiments and analyzed the CMP mechanism. Gao P wrote the manuscript and Ye RP revised it. All authors discussed the results and commented on the manuscript. All authors contributed to the general discussion.

Conflict of interest The authors declare that they have no conflict of interest.

Supplementary information Experimental details and supporting data are available in the online version of the paper.

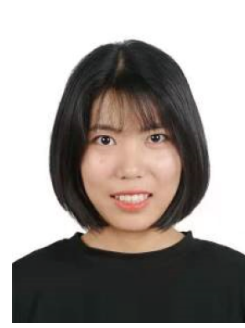

Peili Gao is a Master student at the School of Mechanical Engineering, Dalian University of Technology, China. Her research work focuses on the synthesis of novel abrasives and their application on nanoscale precision manufacturing.

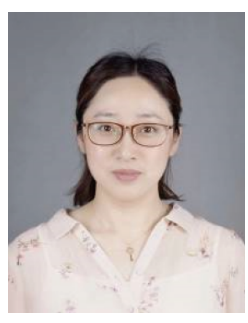

Tingting Liu received her PhD degree in chemical engineering from Curtin University, Australia in 2017. Then she joined Dalian Institute of Chemical Physics (DICP), Chinese Academy of Sciences as a research fellow. She is currently a postdoctor at the School of Mechanical Engineering, Dalian University of Technology, China. Her research interests are applications of nanomaterials and chemical mechanical polishing.

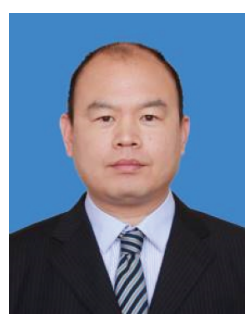

Zhenyu Zhang received his $\mathrm{PhD}$ degree in solid mechanics from Tianjin University, China in 2005. He has been working in the Key Laboratory for Precision and Non-Traditional Machining Technology of Ministry of Education at Dalian University of Technology, China since 2007, and his current position is a professor. His research areas cover ultra-precision grinding, chemical mechanical polishing, nanoscale precision manufacturing, and nanotribology.

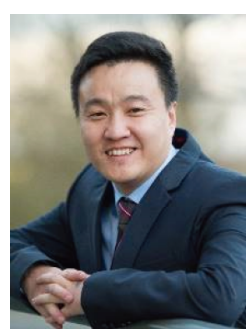

Jian Liu received his $\mathrm{PhD}$ degree in physical chemistry from DICP, Chinese Academy of Sciences in 2008, and worked at the Australian Institute for Bioengineering and Nanotechnology, University of Queensland as a research fellow. After working at Curtin University as a senior lecturer from 2013 to 2017, he then joined DICP as a full professor and group leader of micronanoreactor and reaction engineering. $\mathrm{He}$ also held an adjunct reader position at the Department of Chemical and Process Engineering, University of Surrey, UK. His research focuses on the design of micronanoreactors, porous carbon spheres, and industrialization of homogeneous catalysis in heterogeneous systems.

\section{介孔结构非球形磨粒的制备及其在化学机械抛光 中的应用研究}

郜培丽 ${ }^{1,2 \dagger}$, 刘婷婷 ${ }^{1 \dagger}$, 张振宇 ${ }^{1 *}$, 孟凡宁 ${ }^{1}$, 叶闰平 ${ }^{2}$, 刘健 ${ }^{2,3^{*}}$

摘要 化学机械抛光技术通过抛光液中化学试剂的化学腐蚀和纳 米磨粒的机械磨削双重耦合作用, 在原子水平上去除材料表面缺 陷, 实现全局平坦化表面加工, 现已成为关键零部件和器件材料的 超精密表面制造的关键手段. 在化学机械抛光加工中, 纳米磨粒是 外加机械能向抛光系统输入和转化的媒介. 磨粒的机械性能很大 程度上影响着化学机械抛光加工过程中机械作用的强弱, 决定着 加工性能的优劣. 本文主要针对碲锌镉晶体的软脆难加工特性, 对 传统实心球形磨粒进行了结构和形貌的双重改性, 合成了一系列 长径比可控、介孔结构排列有序的棒状二氧化硅磨料. 与商用硅 溶胶、实心及介孔二氧化硅球形磨粒相比, 棒状介孔磨粒由于其 类弹簧多孔结构和大尺寸接触面积, 在化学机械抛光实验中展现 出优异的弹性变形能力和高质高效超精密表面加工能力. 此外, 通 过分析X射线光电子能谱和其他表征结果, 本文对所提出的绿色环 保化学机械抛光液在碲锌镉晶体化学机械抛光加工中的潜在作用 机理进行了说明, 这将为改善磨料的切削性和难加工材料的精密 制造提供新的策略. 